\title{
CHALLENGING THE FAST FASHION PRODUCT: \\ A METHOD FOR USE-VALUE APPAREL DESIGN
}

\author{
by \\ Jennifer Triemstra-Johnston \\ Bachelor of Fine Arts, York University, 1995
}

\author{
A major research paper \\ presented to Ryerson University \\ in partial fulfillment of the \\ requirements for the degree of \\ Master of Arts \\ in the Program of \\ Fashion \\ Toronto, Ontario, Canada, 2013 \\ (C) Jennifer Triemstra-Johnston 2013
}




\section{AUTHOR'S DECLARATION FOR ELECTRONIC SUBMISSION OF A MRP}

I hereby declare that I am the sole author of this MRP. This is a true copy of the MRP, including any required final revisions.

I authorize Ryerson University to lend this MRP to other institutions or individuals for the purpose of scholarly research.

I further authorize Ryerson University to reproduce this MRP by photocopying or by other means, in total or in part, at the request of other institutions or individuals for the purpose of scholarly research.

I understand that my MRP may be made electronically available to the public. 


\title{
CHALLENGING THE FAST FASHION PRODUCT:
}

\section{A METHOD FOR USE-VALUE APPAREL DESIGN}

\author{
Jennifer Triemstra-Johnston \\ Master of Arts, 2013 \\ Fashion \\ Ryerson University
}

\begin{abstract}
Sustainable apparel design is a discipline based on challenging the status quo. Applying an interdisciplinary approach, this paper integrates the methodologies of research through practice, sustainable design, and material culture to challenge contemporary products found on the fast fashion market. Exploring use-value as an avenue for sustainable design, a typology is developed addressing the identifiers of function, aesthetics, expression, and durability as a method for generating sustainable solutions. The interpretative methods of material culture are adapted into a use-value challenge as a process for establishing sustainable and unsustainable elements embedded within a product. The concept of best practices is introduced as a procedure for assessing the solutions for the creation of alternative prototypes. A case study, challenging children's princess costumes found on the contemporary market, provides an example of how the use-value method for apparel design can be applied to fast fashion products.
\end{abstract}




\section{Acknowledgements}

This project would not have been possible without support and supervision of several professors from the Ryerson School of Fashion MA program. I am indebted to the following professors for their never ending support: Dr. Kimberly Wahl for encouraging me to become a stronger writer; Sandra Tullio-Pow for introducing me to functional design and her guidance as my MA Program Supervisor; Dr. Alison Matthews David for revealing the links between my design work and material culture and Dr. Lu Ann Lafrenz, my supervisor, who gave me the freedom and encouragement to follow tangents, while trusting me to reign them all in. Thank you all for your inspiration and friendship.

There are many other individuals that helped make this paper possible with their ideas, insight, and emotional support. I am grateful to the fellow colleagues I met in the program, who shared my excitement and love for fashion and costume: Elaine, Jen, P.Y. and Tanya, it was a pleasure to embark on this academic journey with you. I am indebted to Carolyn Cross at the Oakville Museum who offered me not only a curatorial internship, but her friendship and advice. I have to thank my friends: Alex, who was my study partner and sounding board; Jan and Nancy, for egging me on and having the faith in me to finish; and Melanie, for reminding how to use a comma.

Lastly I am thankful for my parents and family for their support and encouragement; Marijke, my sister, who showed me what true perseverance is; and Chris, my partner, to whom I am eternally grateful, I could not have made it through the last three years without you. 


\section{Dedication}

For my Mother, who always told me a change is as good as a rest. 


\section{Table of Contents}

Page

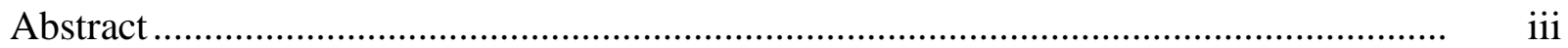

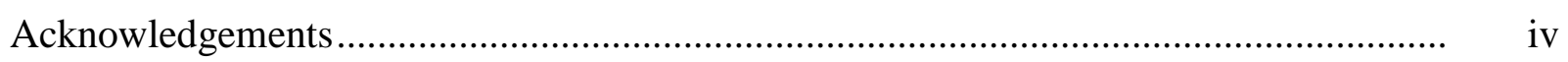

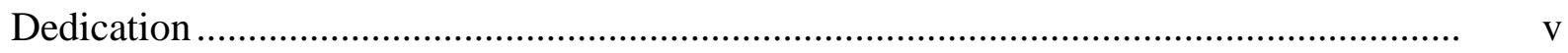

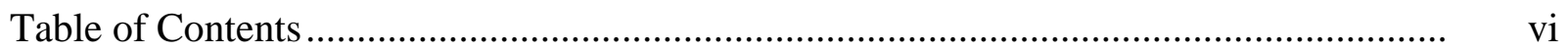

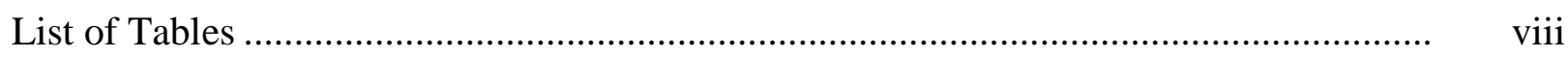

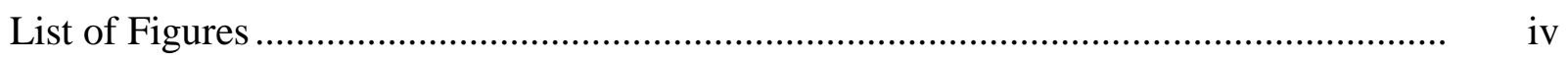

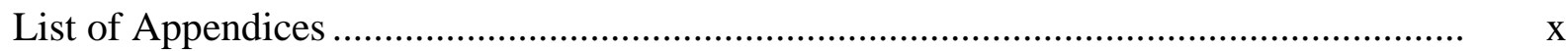

Chapter One: Introduction .........................................................................................

Chapter Two: Methods ............................................................................................ 8

Theoretical Framework: Research Through Practice ............................................... 8

Chapter Three: Contextual Review................................................................................ 12

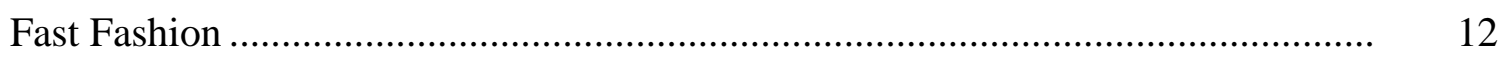

Working in Sustainable Design .......................................................................... 14

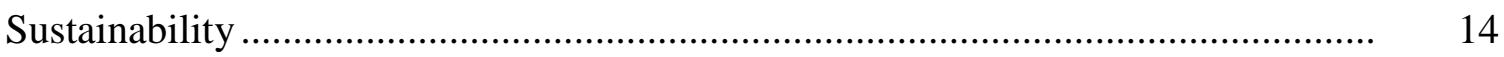

Use-Value as Sustainable Criteria .......................................................................... 17

Use-value apparel design............................................................................ 18

Use-value product design ....................................................................... 23

Sustainable Typologies................................................................................. 24

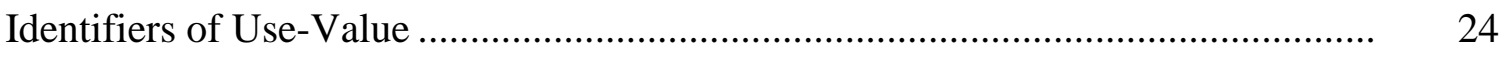

User Need Identifiers ................................................................................... 24

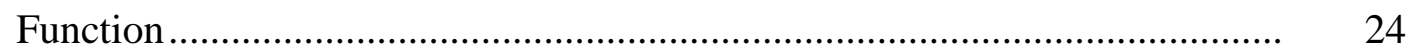

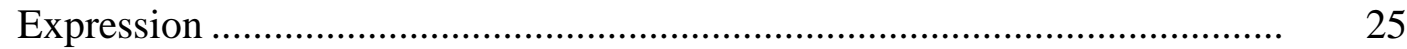

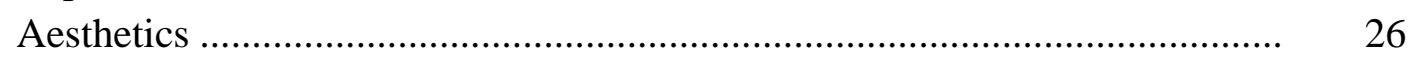

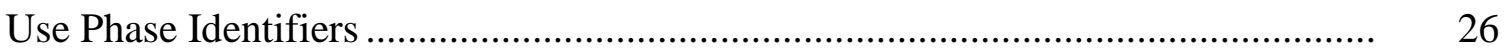

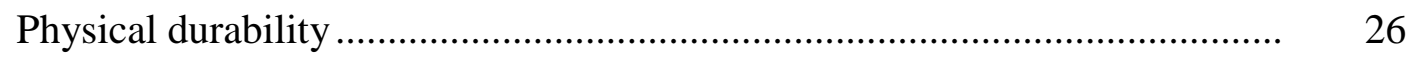

Emotional durability .............................................................................. 27

Potential durability .......................................................................... 28

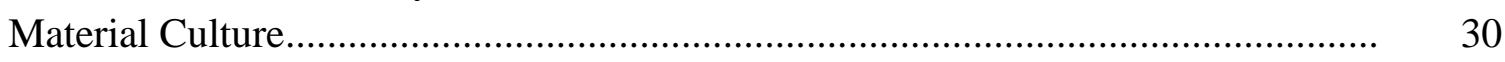

Reflection of belief and value................................................................ 31

Interpretation of belief and value ............................................................... 33

Methods of Interpretation ........................................................................... 38

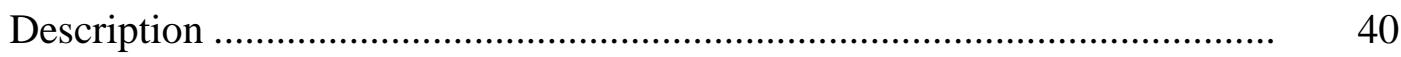

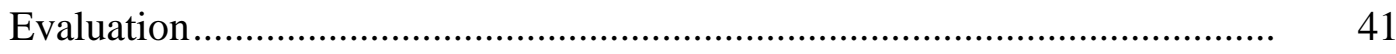

Interpretation/challenge ........................................................................... 43

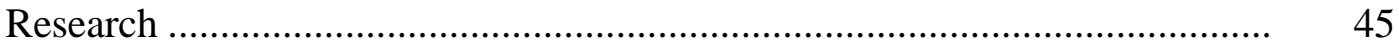

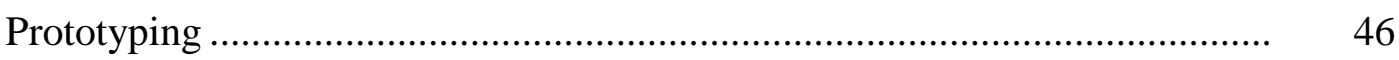


Best Practice ............................................................................................. 46

Process and Perspective of the Use-Value Challenge Method............................... 47

Challenging the Fast Fashion Process ................................................................. 49

Chapter Four: Findings and Analysis ............................................................... 51

Description and Evaluation Stages Summary ................................................ 51

Establishing the Challenges From the Application of the Typology ...................... 55

Generating and Researching Use-Value Solutions........................................... 56

Prototype Design Development...................................................................... 59

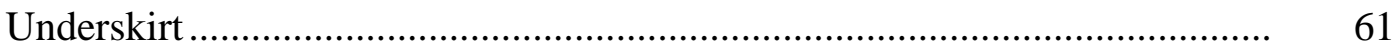

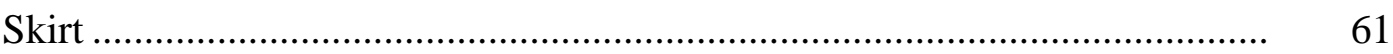

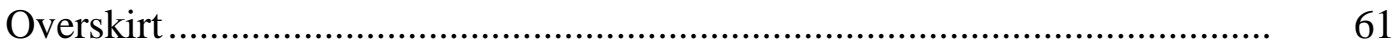

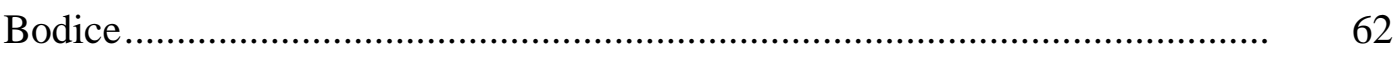

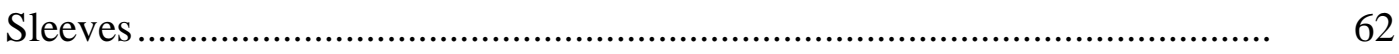

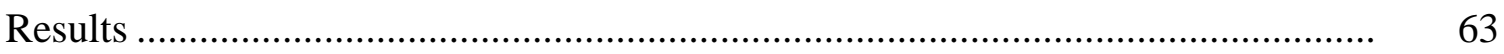

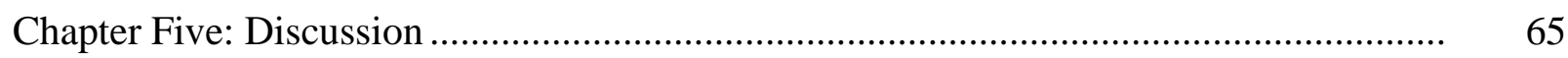

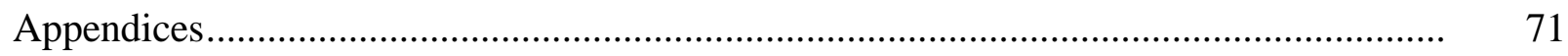

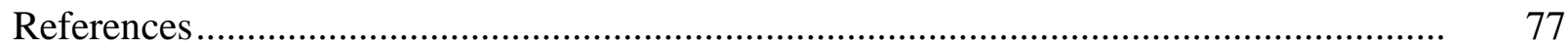




\section{List of Tables}

Table

Page

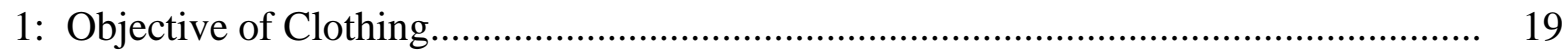

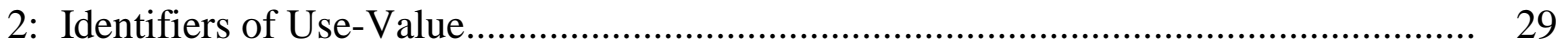

3: Use-Value Typology for Challenging Fast Fashion Products ................................. 45

4: Typology for Challenging a Fast Fashion Princess ............................................. 58 


\section{List of Figures}

Figure $\quad$ Page

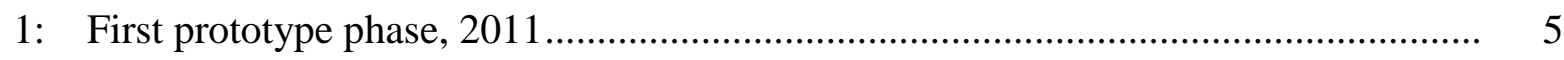

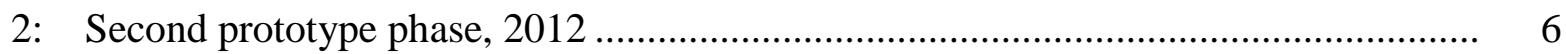

3: Consumer needs model ............................................................................... 20

4: Summary of material culture interpretation and the use-value challenge method ...... 47

5: Disney Store Rapunzel princess costume .................................................... 54

6: Dreampower Cinderella playtime style ............................................................. 54

7: Creative Education Canada princess dress, glitter pink.................................... 54

8: $\quad$ Pink Tulip princess costume prototype....................................................... 60

9: Blue Iris princess costume prototype ........................................................ 60

10: Pink Tulip prototype overskirt options …................................................. 61

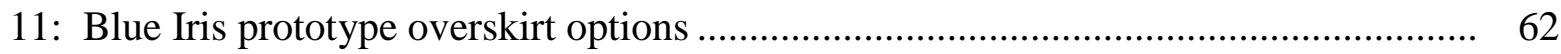

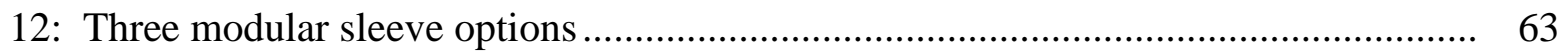




\section{List of Appendices}

$\begin{array}{ll}\text { Appendix } & \text { Page }\end{array}$

A: Description Stage of Use-Value Method ................................................................... 71

B: Evaluation Stage of Use-Value Method..................................................................... 75

C: Interpretations of Disney's Cinderella ................................................................... 76 


\section{Chapter One: Introduction}

Sustainable apparel design is a discipline based on challenging the status quo. Sustainable fashion advocates (e.g., Armstrong \& LeHew, 2011; Black, 2008; Fletcher, 2008; Hethorn \& Ulasewicz, 2008; Niinimäki \& Hassi, 2011; Laitala \& Boks, 2012) encourage designers and product developers to challenge and change current production and consumption methods to promote sustainable fashion practices. For the fashion designer interested in sustainable design, putting the challenge into practice can be daunting and overwhelming. Designers must confront the economic system of fast fashion that is reliant on speed and productivity (Fletcher, 2010), with the vast and ever-changing criteria of sustainability. Literature on sustainable fashion practice tends to offer designers overreaching philosophies about fashion production and consumption systems and numerous solutions to consider during the product development, but no clear method or framework in regards to preliminary product creation or prototyping is recommended. However Armstrong and LeHew (2011) argue the initial design process undertaken by a fashion designer is integral to the sustainability of a product and the environmental impact it makes.

Creative fashion research tends to focus on the design of items for aesthetic values (Bye, 2010) and the subject of fashion often ignores the social interactions, relationships, and consequences stemming from the fact that articles of fashion are worn (Dant, 1999). However new genres for sustainable apparel design are emerging that integrate the experiences and requirements of clients, while working with sustainable materials and processes (Chapman, 2005; Fletcher \& Goggin, 2001; Laitala \& Boks, 2012; Niinimäki \& Hassi, 2011). In recent years, sustainable apparel design theorists have begun to promote product longevity as design principle, concluding that extending the life of an object may result in the optimum use of 
resources and slow cycles of consumption (Chapman, 2005; Fletcher, 2012; Hethorn \& Ulasewicz, 2008; Laitala \& Boks, 2012). However, there is an obvious futility in designing an enduring product if the client has no continuing use or relationship with the item. A designer's efforts should therefore focus not only on durable materials and processes, but also on the usevalue of a fashion item (Chapman, 2005; Fletcher, 2011, 2012; Fletcher \& Goggin, 2001; Fletcher \& Grose, 2012; Laitala \& Boks, 2012; Niinimäki \& Hassi, 2011). While the use-value of apparel has traditionally been derived from assessing and fulfilling the functional and symbolic needs defined by the user (Rosenblad-Wallin, 1985), sustainable apparel design is beginning to examine the use phase of clothing as an important facet of use-value and a means of promoting longevity (Fletcher, 2011, 2012; Laitala \& Boks, 2012; Niinimäki \& Hassi, 2011). In essence designers must now incorporate the potential for future use into apparel design. Although Lamb and Kallal (1992) developed a consumer-needs analysis method for satisfying the functional and symbolic desires of the user, the method does not encompass sustainable criteria related to materials and processes or what happens to the garment after point of purchase during the use phase of its lifespan. While sustainable fashion design literature offers environmental and ethical solutions and case studies, with regards to product materials, processes and life cycles, the research does not provide a design method that satisfies multiple sustainable criteria during the apparel design process. This paper presents my design journey to develop a method for use-value apparel design that challenges the fast fashion product as a process for generating use-value and sustainable solutions in an alternative product.

I do not profess to be an expert on sustainability. My undergraduate degree is a Bachelor of Fine Arts in theatre production and I have worked as a costume designer and costume builder for theatre, opera, and dance productions for more than 15 years. However, my passion for 
costume design has always been sparked by satisfying the demanding needs of physical performance while creating and communicating a believable character or image on the stage for the audience. The requirements of a costume not only are dependent on the performer's needs and desires but also dictated by multiple authorities; for example: directors, choreographers, stage managers, and set, light, and sound designers may also define the functional and expressive needs of the costume worn the performer. Costume designs are also strictly demarcated by budgetary, durability, and laundering concerns. Furthermore, costume designers/builders must include the artistic and communicative elements of costume design while incorporating their own aesthetic preferences and styles into their work.

Costume design and construction is reliant on studying different cultures and societies and their material culture so that the beliefs and the values of the culture can be interpreted and reflected on the stage. In this design scenario, material culture can refer to an artefact, an object created or altered by humans, or the study of artefacts to understand the beliefs, values, and assumptions of a particular culture at a given time (Prown, 1982). The study of material culture also generates design solutions for the functional and physical requirements of a costume.

Designers and builders examine historical and contemporary artefacts to determine how materials, processes, and construction methods were executed in objects to determine how these same elements might be applied or manipulated in a theatrical scenario. Costume designers study existing artefacts to illuminate cultural values and beliefs, while also generating design solutions. Costume design is a fusion of historical and contemporary values, materials, processes, and procedures to develop an ensemble that satisfies the functional demands of performance without impeding the expressive and aesthetic elements of the design. 
Focusing on the fast fashion product as the element to be challenged in sustainable apparel design, I was eager to explore how a similar process of interpretation and evaluation could be applied to contemporary garments to generate elements of use-value for an alternative product.

Taking up the challenge of sustainable fashion design, this paper presents the third stage of an ongoing research through practice study examining and establishing design methods for sustainable apparel. The research was initiated as a deconstruct/reconstruct experiment in which a new garment was created from existing apparel, with the goal of producing zero waste in the process. For the experiment, children's princess costumes were created from second-hand silk wedding dresses. Although the study concluded with a successful re-use of materials, using approximately $95 \%$ of the original garments, it raised concerns in regards to the sustainability of the garments in their entirety. The environmental impacts of additional notions, closures, decorative elements, and dye finishes required to complete the garments were not evaluated. Although successful in diverting second-hand apparel from landfill, it became obvious that the garments would not realistically fulfill the needs and desires of a client in regards to functionality, durability, or cost. 


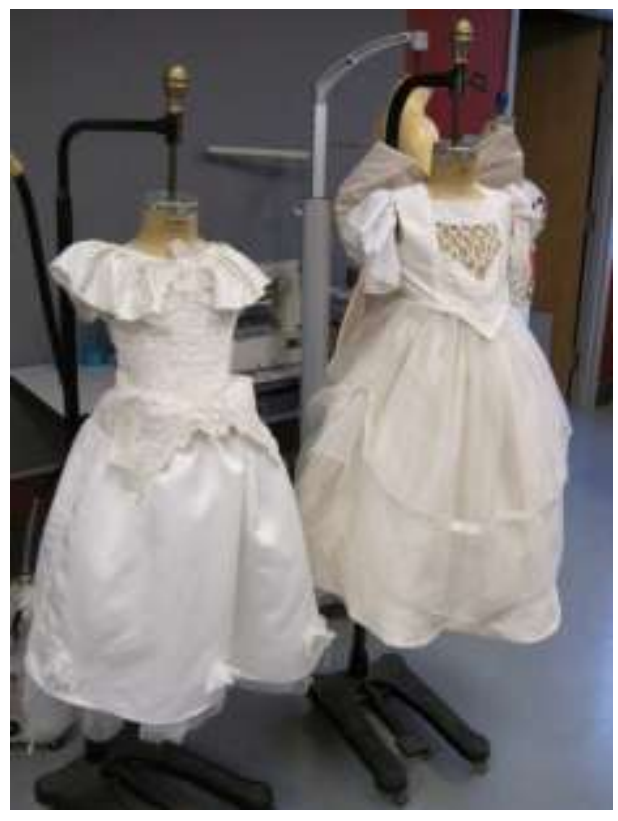

Figure 1. First prototype phase, 2011. Deconstruct/reconstruct exercise to create princess costume prototypes made from repurposed silk wedding dresses.

A user-oriented, participatory design methodology was applied during the second phase of princess costume prototyping. A client was approached and, using the consumer needs model developed by Lamb and Kallal (1992) that addresses the functional, expressive, and aesthetic needs (FEA) of a client, a design criterion for the client was established. It became apparent that positive and negative attributes perceived by the client pertaining to products currently on the market were the benchmark and basis for the client's needs and desires. Applying the criteria stipulated by the client, a prototype was developed responding to the needs specified: durability, multiple users, imaginative play value, and specified aesthetic details in regards to fabric, colour, and decoration. The costume was field tested with the client and her daughter to evaluate the successes and failures of the prototype. Although the second prototype successfully addressed the needs of the client, the user-based design approach did not consider the environmental and ethical impacts of materials, process, and resources in the creation of the prototype. The second 
prototype did however indicate two important areas for future research: the FEA model is successful at developing and promoting use-value within a product and the fast fashion market is a source of inspiration for what not to do.

At the conclusion of the creation of two prototypes, I determined that to encompass sustainable initiatives, a designer needed to address environmental values of materials and processes as well as the needs and desires of the client, essentially the use-value of the product. These conclusions prompted the current stage of research to develop a method in which to challenge a product on the fast fashion market in terms of its use-value while still incorporating sustainable practices in regards to materials and processes.

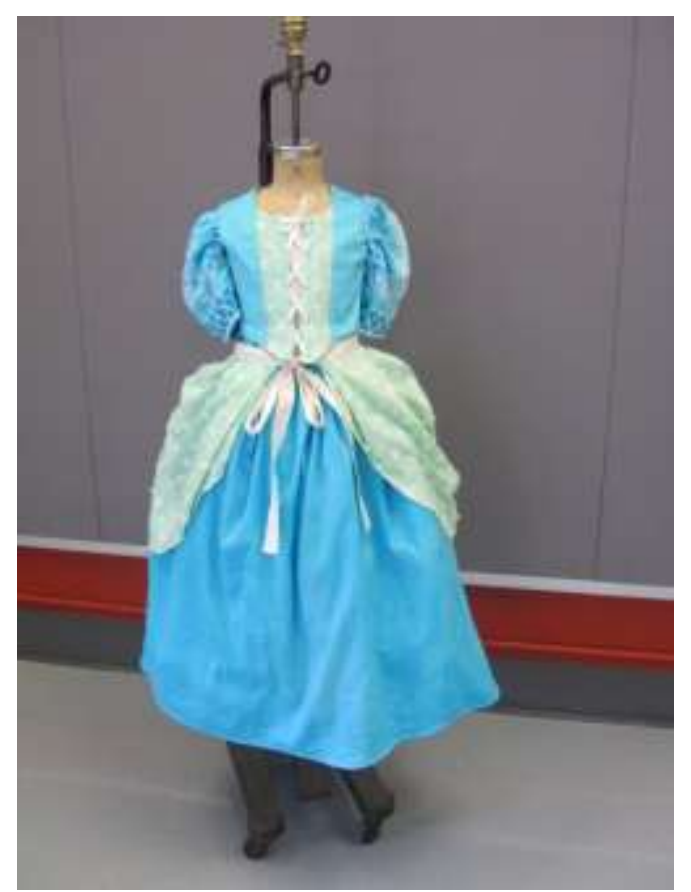

Figure 2. Second prototype phase, 2012. User needs analysis and participatory design process for the creation of a princess costume.

Applying an interdisciplinary approach, this paper integrates the methodologies of research through practice, sustainable design, and material culture to challenge contemporary 
products found on the fast fashion market. My design research is based on the research through practice methodology where the process of my work is as relevant as the resulting artefact. Exploring use-value as an avenue for sustainable design, a typology is developed addressing the identifiers of function, aesthetics, expression, and durability as a method for creating alternative solutions. The interpretative methods of material culture are adapted into a use-value framework for challenging products as a process for establishing both sustainable and unsustainable elements embedded within the product. The concept of best practices is introduced as a procedure for assessing the solutions for the creation of a sustainable prototype. A case study, challenging children's princess costumes found on the contemporary market, provides an example of how the use-value method for apparel design can be applied to fast fashion products. My research is based on three questions that evolved as I progressed through my contextual review and design process:

1. What elements promote use-value in a product?

2. Can material culture studies provide a theoretical framework and methodology for challenging a product in regards to its use-value?

3. Does challenging a contemporary product found in the fast fashion market generate viable solutions for an alternative product? 


\section{Chapter Two: Methods}

\section{Theoretical Framework: Research Through Practice}

Buchanan (2001) proposes that a new design scholarship is emerging in academic institutions with the integration of theory, practice, and production as a means of developing knowledge. Practice-led research is a methodological framework often used to support design research. "Practice-led research is characterised by a focus on issues, concerns and interests that are explored and manifested through the production of creative artefacts” (Mäkelä, 2007, p. 159). Research through practice is a framework for clothing and textile design scholarship that follows the practice-led methodology. Research through practice gains its knowledge not only from the resulting artefact but from the process undertaken to create it. Within the discipline of fashion design, Bye (2010) indicates the initiation of the research through practice is not based on creative or problem solving stimulus, but from a concept arising from practice itself that is contextualized and analysed throughout the evolving design process. Research through practice requires ongoing research and the application of other methods and theories to generate solutions and innovative ideas to change or alter the process of design as well as the artefact. Faced with applying multiple sustainable criteria to a product, research through practice encourages sustainable designers to stay current with relevant sustainable developments, address solutions from alternative sources, and have the freedom to explore different fields for concepts and ideas. The resolution of the design process within the research through practice methodology does not necessarily provide a definitive answer or solution as in problem-based research, but contributes to the evolution of sustainable design by providing multiple solutions and options. Research through practice, in fact, encourages and initiates additional research as one solution that can lead to the next question or challenge to be explored. If anything, the hardest concept for a 
sustainable apparel designer utilizing the research through practice methodology is identifying when to stop, analyze, and present their data and prototyping. For sustainable apparel design, research through practice allows constant review and application of new ideas as one prototype ignites the challenges of the subsequent research, all the while working towards a viable product. Research through practice is a methodology integral to challenging a product on the fast fashion market to create an alternative prototype; it not only offers a method for generating multiple design solutions but provides a scholarly approach for presenting substantiated design research developed through the process that could be applied to other fields and design scenarios.

For practice-led research to contribute to scholarship in the clothing and textile design field, the practical experience of creating the design prototype must be shared and communicated by the designer (Bye, 2010). Although the creation of a prototype or artefact is often considered the conclusion of design practice, in practice led research it is utilized as argument; data to be interpreted and analyzed (Mäkelä, 2007). The relationship between practice and prototype that develops during the design process is integral to understanding the resulting garment and must be considered as part of the research to be presented. Mäkelä (2007) summarizes the requirements for practice led research from the works of Biggs (2002), AHRB (2001), and Scrivener (2002); explicit research questions, specific methods for answering the questions, and a specific context in which the research is carried out. Although for the design practitioner the solutions and argumentation for their research may appear obvious, to substantiate practice-led research the researcher must provide access to the context in which they began their inquiry, the practice that led them to the artefact or prototype, and the evidence that supports the conclusions of their research. 
To establish credible data in research through practice apparel design, Bye (2010) suggests using triangulation, the application of multiple methods to collect data. The use of several of methods of data collection corroborates a designer's observations from several perspectives, establishing transparent research. Methods may include contextual reviews, sketches, photographs, mind mapping, prototyping, typologies, charts, personal reflection, interviews, visual journals, and exhibition.

My research process utilizes a contextual review, a creative process journal (CPJ), and prototyping to develop and support a use-value apparel design framework applying the interpretation methods of material culture.

A contextual review is an expanded literature review that is more practical in nature, reviewing and evaluating materials, artefacts, processes, exhibitions, and other designers' methods (Bye, 2010). Walker (2006) proposes preliminary research of objectives and criteria should be executed before prototyping, arguing that contextual research informs not only the practice but the acceptance and comprehension of the final product. The contextual review frames design practice within scholarship, placing the design project into the realm of research rather than satisfying creative inspiration. It should be noted that a contextual review is not finite but continues throughout the design practice since evolving solutions and concerns require additional research.

For the purpose of this research project, material culture was investigated to consider possible applications to developing a sustainable and use-value apparel design framework. Existing apparel design and use-value design elements were examined to aid in the creation of a typology to address unsustainable use-values in current products on the fast fashion market. An ongoing exploration of sustainable criteria, applications, and case studies were considered for 
their possible contribution to solutions to the challenges that were developed from the established typology.

The CPJ could be viewed as an ongoing, visual contextual review. The CPJ is likened to an interview transcript or case study with multiple forms of evidence (Gillham \& McGilp, 2007). A comprehensive CPJ continued to evolve through the research through practice stages of this study. It includes written reflection, numerical data relating to size and fit, patterns, sketches, technical drawings, process diagrams, inspirational images, photographic records of progress, and historical research. The CPJ was analyzed and interpreted during the research process to provide information for further elucidation and inspiration. Due to its size and format, the entire CPJ created throughout this research project is not included in this paper; however selected images and charts are presented as support material to the research findings.

A prototype is a form of artefact produced through practice. It is a response to the criteria or problem established in the contextual review. In the conclusion of the research, the prototype acts to communicate the relationship between physical objects and theoretical design concepts (Mäkelä, 2007). The prototype is the culmination of the experience and tacit hands-on knowledge of the designer, which is communicated in research through practice.

Two princess dress prototypes were created during this phase of design research. They are presented as a case study within this paper. 


\section{Chapter Three: Contextual Review}

\section{Fast Fashion}

To understand the challenge presented by advocates for sustainability, one must first consider why there is a need for change in fashion practice. Fast fashion is a term that implies speed and often refers to the ever-increasing rate at which designs move from the catwalk into the retail environment and the production times facilitating the quick turnaround. However, Fletcher (2010) argues fast fashion is a result of the competitive practices of fashion houses and the demands of companies for increasing profit. To stay competitive, companies endeavour to find faster, more economical ways to satisfy and flood the market with their product. Fletcher (2010) outlines large-volume manufacturing methods, using the most cost-effective labour, materials, and processes for rapid fabrication and distribution as foundations of fast fashion practice. In 2005, when the Multi-Fibre Arrangement (MFA) agreement regulating international textile import and export quotas came to an end, countries like China, Bangladesh, and India began to offer lower production costs. The end of the MFA contributed to the fast fashion dilemma. With worldwide access to low-cost labour and cheap manufacturing in the global market, companies produced inferior, disposable garments to stay competitive. The aggressive fast fashion system may be considered lucrative for corporations and fashion houses but it is detrimental to the world's ecosystems. In regards to environmental and ethical concerns, fast fashion causes resource depletion, pollution, climate change, and socioeconomic concerns such as poor wages and working conditions for garment workers (Fletcher, 2010).

Although fast fashion may appear to offer more choice to customers, Fletcher (2010) concludes that due to the standardized methods of mass production, there is uniformity between competing fashion chains and, with the loss of local, independent designers unable to compete 
within a profit margin, there is a lack of options for the consumer. For designers working within the fast fashion sector, it is difficult to include elements of innovation and longevity while competing for market share-whereas the independent or niche market designer has to consider how much a customer is willing to invest for an alternative product that may push the boundaries of what is acceptable in a homogenized market.

Fast fashion has also affected the relationship consumers have with fashion items. According to Walker (2006), products are often designed with the goal of expanding market share and profits and not as what he describes as meaningful material culture. Fletcher (2010) and Walker (2006) both contend that with the market routinely flooded with cheap products, presenting low production value and little durability, consumers view purchased items as disposable, inexpensive, and easy to replace. According to Simmel (1907), "What is distressing is that we are basically indifferent to those numerous objects that swarm around us, and this is for reasons specific to a money economy; their impersonal origin and easy replaceability" (as cited in Dant, 1999, p. 138). With the move of production overseas, both Fletcher (2008) and Walker (2006) believe that the consumer is no longer aware of the materials, makers, or skills involved with creation, causing them to be disengaged with products. Walker (2006) argues consumers no longer have the desire to maintain or upgrade the items since both emotional and financial investment is low. Fletcher (2008) is more specific in terms of the relationship between clothing and the wearer of fashion: because consumers are no longer aware of the skills needed to construct clothing, they have no inspiration to alter, maintain, or finesse garments and use consumption as the one of the only means to change or update their wardrobe. 


\section{Working in Sustainable Design}

The goal of creating a sustainable garment becomes daunting when considering applying sustainable initiatives and values to the dominant fast fashion system. Multiple definitions, contexts, critics, and variables of sustainable practice exist in every field of design theory and practice. For anyone considering sustainable design, it is imperative to understand not only the origin of the concept but the vast parameters of sustainability. To be comfortable creating within the realm of sustainable design, one must develop one's own sustainable contexts and challenges to pursue, always with the understanding that the criteria, values, and possible solutions may evolve with every new project, development, and subsequent scholarly research. Ideally, in the future, sustainability will become another value that is automatically included within the elements of design. According to Chapman (2005):

Many practitioners are beginning to believe that there should be no such thing as sustainable design, claiming that it is wrong to departmentalize environmentally aware design practice as it should simply be integrated within conventional design practice without ceremony. Essentially, catering for the needs of the natural environment is simply another element of good design. (p. 173)

However, at this point in time, apparel designers wanting to incorporate environmental and ethical concerns within their work must develop their own model of sustainable fashion design process from the numerous definitions and criteria currently available.

\section{Sustainability}

Since 1987, when sustainable development was outlined by the World Commission on Environment and Development (1987) as meeting the requirements of today without the endangering the resources of the future, sustainability has evolved to include the social, 
economic, and environmental factors that work together to find sustainable solutions (United Nations General Assembly, 2005). In recent years, sustainability has become a catchphrase used to promote an organization's environmental or ethical initiatives. According to Farrer (2011), "The misrepresentation and cherry picking of values from the sustainable agenda, particularly over the last decade, by business, marketers, and politicians and even by education, has led to the movement becoming hijacked for commercial purposes" (p. 20). In many ways the focus of sustainable design has become misguided, offering solutions that continue to support consumption and profit rather than confronting the reason for resource depletion (Chapman, 2005). In terms of sustainable fashion design, the goal has become to maintain a healthy relationship between people, processes, and the environment (Hethorn \& Ulasewicz, 2008); while for the fashion industry, economics are prioritized and the term refers to satisfying the needs of people, profits, and the planet (Farrer, 2011). Ecological fashion, once thought to embrace the three Rs (reduce, reuse and recycle), now encompasses not only every phase of the garment life cycle from design inception, production, consumption, and disposal, but also the relationship consumers have with their clothing. Walker (2006) suggests the success of sustainable design is impossible to define or achieve as it hinges on varying perspectives, with multiple solutions, yet he argues the sustainable challenge is worthy since every innovation and development adds to the evolving scholarship of what is possible.

The very thought of applying sustainable initiatives to fashion is considered a paradox by many working in the field (Black, 2008, Hethorn \& Ulasewicz, 2008; Walker, 2006), for they question: how is it possible to align the values of sustainability with the speed and profits of contemporary fashion? However, several fashion concepts may be considered advantageous within the realm of sustainable design. Clothing and apparel is worn and displayed by everyone 
suggesting the scope and potential for change is substantial (Hethorn \& Ulasewicz, 2008). The creative and problem-solving processes of fashion practice may provide future solutions and innovations that are integral to the sustainable design method. Considering the numerous avenues from which sustainable fashion can be approached, there are multiple solutions for creating new products and contexts in which to educate consumers. The process and design of fashion deals with change and change can be used to sustainability's advantage. As new alternative products become fashionable, they will encourage interest and understanding in sustainability while offering original, imaginative characteristics (Walker, 2006). In terms of sustainability and the speed of modern fashion production, Fletcher (2008) challenges "It requires us to find ways to extend the value and use of some products while simultaneously learning how to express the fashion moment while minimizing the impact of material consumption" (p. 164).

For the sustainable apparel designers, with such overreaching and multiple definitions to reference, they must determine their own set of sustainable values and parameters in which they wish to work. Multiple guides offer advice and case studies on life cycles, materials, processes, and user needs to consider when designing a sustainable fashion item (Black 2008; Fletcher, 2008; Fletcher \& Grose, 2012; Gwilt \& Rissanen, 2011; Hethorn \& Ulasewicz, 2008). While the guides offer different avenues from which to approach sustainable apparel design, a method or process on how to apply these during design practice is not suggested.

After applying two sustainable initiatives to the design and creation of princess costumes for young children (the first, re-use of a textile and the second, addressing user needs) I was frustrated with the fact that applying individual avenues for sustainable designs did not simultaneously address sustainability with regards to materials, processes, and satisfying the 
needs of a client or user. These conclusions prompted the current stage of research: to develop a method in which to challenge a product on the fast fashion market in terms of its use-value while still incorporating sustainable practices with regards to materials and processes.

\section{Use-Value as Sustainable Criteria}

As mentioned earlier, new genres for sustainable apparel design are emerging that integrate the experiences and requirements of clients, while working with sustainable materials and processes (Chapman, 2005; Fletcher \& Goggin, 2001; Laitala \& Boks, 2012; Niinimäki \& Hassi, 2011). The relationship between the consumer and a product has become the focus of promoting use-value for extended lifespan within the field of sustainable apparel design. However, concerns for use-value have arisen not only out of lifecycle thinking but issues with contemporary consumption patterns and the significance of the product's value. Many issues of consumption are similar to the concerns of fast fashion; due to the constant need for stimulus, and the disappointment of unfulfilled expectations, consumers dispose of their garments quickly (Chapman, 2005). The objective of fashion itself may contribute to this dilemma since, according to Chapman (2005), function and satisfying physical needs are rarely a criteria of design in fashion and "function serves as a placebo value, a myth that justifies the existence of what is oftentimes a superfluous object” (p. 40). According to Armstrong and LeHew (2011), a product that has value and satisfies sustainable initiatives may create a relationship between consumer and product, so the consumer cares about its lifecycle and value in terms of longevity, maintenance, and upgrades. Ehrenfeld (2004) concludes "Our artefacts need to be designed to support conscious choice and reflective competence rather than blind consumption. They should produce long-lasting human satisfaction so that the addiction to consumption will abate" (p. 7). 
Use-value apparel design. The most obvious avenue for creating use-value would be to satisfy the needs and desires of the consumer. Although aesthetics and artistic inspiration are often believed to be the creative stimuli behind fashion design, methods have been developed to integrate user needs into the design process. Often, user needs analysis and design methods focus on functional apparel design; clothing that has specific requirements in terms of the physical parameters emerging from employment, military, sporting or medical scenarios. However, the methods of functional design can be applied to apparel design in general. Armstrong and LeHew (2011) suggest that the functional apparel design solving process and subsequent frameworks could be adapted to offer sustainable fashion design solutions. With the application of functional design frameworks to sustainable fashion design, there is an opportunity to build a relationship between the user and the garment based on needs rather than profit-driven trends.

Rosenlad-Wallin (1985) developed a user-oriented apparel design method based on determining the desires and needs of the user and their use situation demands as the criteria to be satisfied in a subsequent design. She determined the client's needs might reflect both functional and symbolic values and concentrated on developing use-value rather than exchange-value as the goal of the design process. Rosenblad-Wallin defines how these values and needs are formed, categorizing them into physical, emotional, and legislative contexts:

The functional values are formed in a relation between man, the product and the actual environment, while the symbolic or non-material values arise on a relation between man, the product and the socio-cultural environment. The symbolic values originate in man's emotional judgement of the product. (p. 279)

The third demand is considered a superior demand that is usually defined by imposed standards from an outside governing body or organization. 
Table 1

Objective of Clothing

\begin{tabular}{ll}
\hline Functional values & Symbolic values \\
\hline Protection/security/survival: & Self-esteem \\
climatic & State of mind \\
environmental & Group membership \\
Comfort: & Decoration \\
thermal climate & Fashion \\
ease of movement & Respectability \\
weight/load & \\
fit & \\
pressures on the body & \\
friction against the body & \\
tactility & \\
static electricity & \\
\hline
\end{tabular}

Source: Rosenblad-Wallin (1985, p. 280).

Lamb and Kallal (1992) suggest that function alone is not enough to satisfy the user but expressive and aesthetic values must also be considered. They propose a conceptual framework with design criteria that develops from the functional, expressive, and aesthetic needs (FEA) of the consumer. These values also coincide with sustainable initiatives in terms of the desires and needs of the wearer (Fletcher, 2008; Hethorn, 2008; Laitala \& Boks, 2012).

Lamb and Kallal (1992) outline the different concerns for the FEA model. Functional criteria concentrate on developing clothing in terms of utility, examining issues of comfort, fit, and mobility. Expressive needs consider the cultural meanings and messages represented through the garment. Aesthetic requirements are based on concepts of beauty and elements of art. In order for the suggested design solutions to be acceptable to the client, the social and cultural 
beliefs of the client must be considered. They also advise that the three classifications of need (FEA) are interconnected, and their relationship to each other might change with each garment and client.

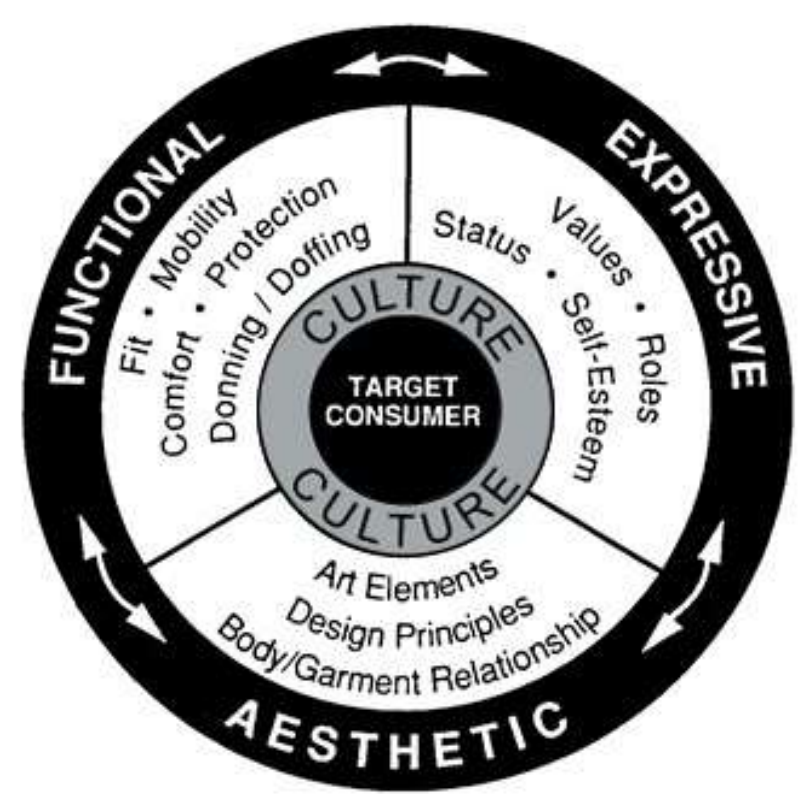

Figure 3. Consumer needs model. The functional, expressive, and aesthetic considerations for user needs apparel design (Lamb \& Kallal, 1992, p. 42).

The user needs analysis framework is beneficial for generating a list of criteria for what a client or user thinks they need in a garment; however, the method is based on perceived ideas of what the objective of the garment should be. Often user needs analysis works with a garment already in production or on the market and the user needs analysis develops solutions and ideas off an existing model to suit the needs of a client. This process does not necessarily incorporate sustainable values in regards to environmental impact of materials and procedures, nor does it take into the consideration the reality of use of a garment after purchase. The concept of the use phase of a garment has become the focus of sustainable apparel scholars who examine disposal habits, garment maintenance, and design for the possible future of a garment. 
Lataila and Boks (2012) examine the post-purchase relationship of the user with regards to maintenance and disposal habits. Using quantitative surveys, qualitative interviews, and laboratory testing, they explore the motives behind the disposal of clothing and the maintenance of apparel. From their research they discovered the main reason for disposal was degradation in quality and issues with fit while people tended to keep their favourite items of clothing longer due to an emotional attachment with an item. Laitala and Boks suggest a designer first satisfy the needs and desires of the client using Rosenblad-Wallin's (1985) functional, symbolic, and superior needs analysis and then consider individual tailoring, customization, and multiple styling as options for building a relationship between the garment and client. Although they conclude education is needed to provide people with the skills and knowledge to fix and alter clothing, for the clients who are willing to repair their garments, clothing should be constructed with additional seam allowances and the possibility for visible mending to be incorporated into the aesthetic of the garment. Laitala and Boks conclude designers must address two factors for longevity: designing for technical and social durability.

Niinimäki and Hassi (2011) suggest sustainable solutions developed in fashion niche markets should be applied to the fashion system as a whole. They promote design solutions that encourage a relationship of involvement from initial purchase through to the use phase of the garment; integrating customization, modular structures, products that have to be assembled or adjusted for personal use, co-creation, and open source design into the design practice. They stress that the features of quality and durability within a garment will allow for longer and more demanding use of a garment thus enabling the product to be upgraded, updated, repaired, or become part of a rental or sharing service. Although Niinimäki and Hassi discuss several design 
strategies originating from niche markets that promote future use-value of a garment, they do not provide a method for applying these initiatives during the apparel design process.

Fletcher (2011) launched the Local Wisdom Project to generate qualitative data regarding people's interactions with clothing post-purchase:

The project's premise is that sustainability can emerge from a wealth of simple interactions and in fashion it has potential to flow not only from a garment's design and production supply chain, but also from the choices we all make as users on a daily basis: how we select, wear, care for and connect with our garments. (p. 166)

The project invites people to tell the story of a piece of clothing based on one of nine categories:

- $\quad$ garments that are shared between people;

- $\quad$ garments that have never been washed - and aren't leather;

- $\quad$ garments that have the character of a particular place in them;

- $\quad$ garments that link you with the natural world;

- $\quad$ garments that catch your attention each time you wear them;

- $\quad$ garments that tell the story of how they’ve been used;

- $\quad$ garments that are made up of separate pieces that can be interchanged;

- $\quad$ garments that make you feel part of a community (but not a uniform);

- $\quad$ garments that are enjoying a third, fourth or fifth life.

( Fletcher, 2011, p. 169)

The stories are recorded and the garments are photographed. From the project's findings, Fletcher concludes sustainable designers have to address the user of fashion in regards to action and engagement rather than ownership, ideally promoting a quality user experience. In a 
subsequent article about the research project, Fletcher (2012) applies the term "craft of use" to the creative process and activities that take place with consumers and their garments postpurchase that extend the life-span of the item.

Use-value product design. Armstrong and Lehew (2011) suggest that a new sustainable design paradigm may be evolving from initiatives developing in other design fields that could be applied to fashion applications in design and product development. Different fields of product design have begun to investigate the longevity of products in regards to the relationship that forms between the user and contemporary products. Walker (2006), who researches sustainable product design, suggests designers should revaluate and challenge contemporary products as material culture to consider social and environmental issues in the hopes of creating sustainable alternatives. He concludes that due to the overseas mass production of products designed for aesthetics, consumers no longer respect, invest in, or participate with modern goods. $\mathrm{He}$ advocates the design of meaningful material culture as a solution for sustainable design to foster a new relationship between products and consumers. Whereas Walker examines the relationship of function and aesthetics and keeping the life cycle of a product within the local geographical community as a means of creating more meaningful culture, Chapman (2005) articulates emotionally durable design as a new genre of sustainable design that develops emotional and empathetic relationships with products. Examining the psychology behind the creation of waste and the disposal of products, Chapman argues modern products have become icons and symbols of status where a product's value is a symbol of meaning rather than a functional or experiential value. He equates waste with physically durable products that are lacking in what he has termed "emotionally durable design." Chapman advocates for products designed with users' emotional 
values in mind, integrating experience, participation, narrative, and evolution in a product's design elements to reduce consumption and waste.

\section{Sustainable Typologies}

To consider the relationship between sustainability, aesthetics, and functionality in his field of product design, Walker (2006) develops a typology that outlines the seven aesthetic characteristics common to manufactured electronic products. The typology charts an aesthetic identifier, a description of how it is achieved within the product, and its relationship to unsustainable practice. Walker's typology aids the designer in setting up a context from which to determine unsustainable practices related to a product's aesthetics; however, a similar typology could be organized addressing the use-value identifiers of fast fashion garments.

\section{Identifiers of Use-Value}

I propose six identifiers of use-value that could be challenged in a fast fashion product, generated from the preceding research on use-value initiatives. The first three identifiers are function, expression, and aesthetics; developed from the user needs analysis frameworks of Rosenblad-Wallin (1985) and Lamb and Kallal (1992). It stands to reason that if a product does not fulfill the perceived and initial needs of the user or the objective of the item, it will not be considered worthy of investing in or caring for. I have expanded the user needs framework to incorporate additional initiatives of sustainability.

\section{User Need Identifiers}

Function. The basic needs of function deal with fit and comfort. As Laitala and Boks (2012) noted in their findings, fit was one of the major reasons for the disposal of garments. Fit can be considered in terms of both fabric and construction choices. Fitting concerns often pertain to whether a garment can increase and decrease in size for comfort, growth, or sharing 
opportunities. Donning and doffing, often related to fit, should be considered for ease and simplicity. Comfort often relates to the physiology of the body regarding temperature, pressures on the body, rubbing, static electricity, and ease of movement.

More advanced issues of function arise when a garment must function or perform in specified conditions in regards to the user. Work, health, medical, performance, sport, aging, and environmental scenarios all propose functional design challenges. The introduction of smart fashion involving wearable technology has expanded the needs of functional design to encompass clothing designed with innovations such as speakers, lights, monitors, and medical apparatuses. Although functional needs within apparel design often deal with specific usedemand scenarios, I would suggest that with the current trend of disposable fast fashion, the garment should be evaluated in terms of how well it fulfills its objectives and promoted design features.

Expression. For Lamb and Kallal (1992) expression is the reflection and acceptance of roles, status, and self-esteem, concerning the meanings and messages reflected in the garments and how the garments are styled or worn on the body. A style, silhouette, or embellishment can be a reflection of expression as it can reference a historical time period, culture, or stereotype. It should be remembered that the criteria for acceptance and respectability of expression is not necessarily determined by an institution or the media but also by a cultural social group either mainstream or subversive.

An issue of expression that I would suggest has become prevalent in contemporary society is the idea of branding, an identifier that separates one product from another. The reflection of brand, either through label, insignia, or design elements has become one of the primary functions of clothing to show status and prestige, often superseding the use-value of a 
garment. According to Chapman (2005), the experience a user has with a product may be tied to the associations and values represented and reflected by the brand of product.

Aesthetics. Aesthetics are often influenced by current trends, resulting from technological advances, popular culture, social action, characteristics relating to the brand, and the creative inspiration of the original designer. The identifier of aesthetics also encompasses the way the garment is worn on the body and is dependent on what is acceptable and attractive in regards to the contemporary ideals of beauty. Aesthetics can be evaluated in terms of elements from art and design fields: patterning, line, space, density, design principles, and colour.

Materials, processes, finishing techniques, style lines, and silhouette are all factors that affect aesthetics and can be challenged with regards to sustainable criteria.

\section{Use Phase Identifiers}

The user needs identifiers outline the needs and desires of the clients prior to the use phase of the garment. Use-value identifiers that reflect the use phase of an item are contingent on what happens between the garment and the owner post-purchase and are linked to concepts of durability. Referring to the previous research into sustainable values of lifespan and longevity, I would define durability into three different identifiers of use-value: physical, emotional, and potential durability.

Physical durability. Physical durability is dependent on the strength and durability of the materials, finishes, and construction processes. The durability of an object is only as strong as its weakest link, implying that such design details as notions, stitches, zippers, embellishments, dye finishes, trims, and linings have equal strength and lifespan (Fletcher, 2012). The results of Laitala and Boks's (2012) research indicated that the degeneration of a garment was one of the main motivations for disposal. 
Issues affecting physical durability relate to wear and tear from laundering procedures as well as wearer habits. Stains, pilling, stretching, fading, and fraying are characteristics of wear and tear that could be considered negative attributes. Therefore, physical durability relies on quality materials and workmanship to enable users to wear their clothing longer.

Emotional durability. Chapman (2005) maintains modern design practices are creating durable waste that results from the lack of relationship with the user. He believes product longevity is the solution to slowing consumption and saving resources, but that durability is reliant on emotional durability as well as physical. His theory supports the design process of embedding experience, narrative, and evolution into products to promote empathy with the product. His suggestions for accomplishing this task are designing products with possibility, multiple meanings, and exploration. Fletcher (2010) and Walker (2006) contend that engagement can be promoted by a local infrastructure of material sourcing, design, production, upgrade and repair services accessible to the consumer so that a relationship is formed between materials, maker, and user. Historically, before clothing was mass produced, a relationship developed between the traditional tailor, dressmaker, or milliner who would have discussed options and subsequently designed, built, and upgraded fashion items for a client. The consumer was personally involved with the decision-making process and the creation and upkeep of a garment - a process that is believed to promote engagement and investment in the item.

The way the surface of a fabric ages is thought to be a possible method for encouraging narrative in a garment. An example of this phenomenon is denim used in the construction of jeans. Denim reflects the creases made by the wearer's body and areas of wear over time by turning lighter in colour than the rest of the fabric. The aging of the fabric offers a personalized, individual patina to the jeans while the fabric softens with use, often taking on the shape of the 
user's body (Townsend, 2011). Other options for fabric aging include staining, fading, and fraying.

Customization, interactive components, modularity, and multiple styling are additional methods that are considered to promote engagement.

Potential durability. Designing for emotional durability is still a process of addressing user needs, albeit metaphysical ones. Designing for what I would term potential durability is about creating a user experience that no one, not the designer or subsequent owner of a garment, has any prior knowledge of. Although Fletcher (2012) concedes that both physical and emotional durability will facilitate the "craft of use," she maintains consumer education involving sewing and styling skills is required to promote user experiences with their clothing. Niinimäki and Hassi (2011) encourage future use design features ranging from product upgrades and maintenance to sharing opportunities. Although these services would be part of a marketing and development of a product, they could inspire design choices during the initial design process.

Until more research is made available and solutions are suggested with regards to the use phase of apparel, I would argue that designing a garment with quality and the ability to be altered is integral for promoting potential durability. The strategic placement of seams and additional and accessible seam and hem allowances allow a garment to be altered and tailored for future modifications of the garment. This is a procedure utilized by theatre and opera companies in the design and construction of costumes that are used by multiple performers for achieving a variable, yet tailored fit. Fabric choices should accommodate surface changes in the form of dye, paint, imaging, and/or age in an interesting manner while having properties that allow for being repaired, patched, or darned. The designer is embedding options for future use within a garment use when implementing the design concept of potential durability. 
Table 2

Identifiers of Use-Value

\begin{tabular}{ll}
\hline User needs & Use phase \\
\hline Functional & Physical durability \\
Expressive & Emotional durability \\
Aesthetic & Potential durability \\
\hline
\end{tabular}

Having established the identifiers of use-value, I had to determine a method for challenging a garment with the criteria, or else I would be providing yet another guide for sustainable design. In my initial research into sustainable design, I noticed that Walker (2006) and Chapman (2005) both refer to products as material culture in their discussions about product longevity. Both Walker and Chapman advocate a new form of sustainable product design that focuses on the relationship between consumer and product, encouraging designers to consider the values associated with material culture. This new method for sustainable product design emphasizes the creation of future material culture, whereby the designer considers the relationships and values embedded in the product. However, the term is used more as a catchphrase than a definition and the nuances of the field of material culture are not explored or examined in regards to sustainable design. This oversight encouraged me to explore the methodology and methods of material culture as a means to interpret fast fashion products to generate design solutions related to use-value. 


\section{Material Culture}

Within the design scenario of sustainability, a product is described as material culture; however, as mentioned before, material culture can refer to an artefact, an object created or altered by humans, or the study of artefacts to understand the beliefs, values and assumptions of a particular culture at a given time (Prown, 1982). Whether considered as object or a scholarly pursuit, material culture is concerned with the social relationship between the object and culture. Prown (1982) summarizes:

The underlying premise is that objects made or modified by man reflect consciously or unconsciously, directly or indirectly, the beliefs of individuals who made, commissioned, purchased, or used them, and by extension the beliefs of the larger society to which they belonged. (p. 1)

Fashion garments, accessories, and clothing obviously fall under the definition of material culture since they are both made and altered by humans. How fashions are worn on the body is also understood to be an alteration of an object and indicates the process of fashion is also considered as material culture (Severa \& Horswill, 1989). Fashion as material culture could then be considered as traditional artefact in historical context or as a product in a design scenario.

Through my research into material culture, I discovered that a relationship exists between material culture and sustainable design that focuses on the artefact and value. The premise of material culture offers designers justification for the creation of alternative products. The methods of material culture provide techniques and processes for not only objectively interpreting beliefs embedded in contemporary items but also examining how these articles of fashion are used and experienced, in the hope of adding use-values and sustainable values to future designs. If sustainable designers consider creating more meaningful material culture as a 
possible solution for embedding use-value in a product to lengthen its lifespan, it is imperative that they understand the implications, values, and methods of material culture.

Reflection of belief and value. Both material culture and various design fields consider the values and context of the society in which an article is used. Material culture is an interdisciplinary study considering not only the artefact and who made and used it, but also the society from which it originated, to cross-examine and substantiate findings. In the process of fashion design, societal values and cultural principles take an active role in decision making. Designers are influenced by the society in which they create by either following or flaunting contemporary conventions, often using historical contexts as inspiration for avant-garde styles. Cultural contexts are integral to functional apparel design, (garments with specific technological or physical requirements for health or work scenarios), to offer design solutions that are acceptable to contemporary users (Lamb \& Kallal, 1992). Within the realm of sustainable design, Walker (2006) states it is imperative that designers question the cultural values associated with contemporary products to critique the negative consequences of modern manufacturing and consumption and address these issues in future designs.

It is the reflection of society's values in products that offers an inception point and justification for a designer to pursue the creation of alternative product designs and promote a shift towards sustainable production and consumption. Prown (1993) deduces that if artefacts are a reflection of a society's values and belief, then as a society undergoes transformation and changes, an artefact would change according to the new cultural ideals. The reflection of ideals in products suggests there is a reciprocal relationship between products and consumers, indicating that if products embedded with sustainable values are consumed by society, then the products are reflecting evolving ideals in regards to environmental and ethical concerns. 
Specifically in regards to fashion and clothing, Rudd and Lennon (1994) suggest that we actively create our appearance in response to a cultural ideal through process of dressing ourselves. Then we can conclude that the very characteristics of fashion, to mirror what is prevalent and popular, could reflect sustainable values designers embed in their designs. Beard (2008) and Black (2008) suggest a paradigm shift has begun in the fashion world, with consumers' desire for eco-friendly products but advocate for the continuous evolution of innovative, sustainable, yet stylish products to keep consumers excited.

Prown (1982) examines the many facets and elements that can be considered as possible catalysts for change within a product. The following passage could be considered a call to arms for the sustainable designer, even though it is a summation for how to interpret material culture. The material culturalist is, therefore, necessarily interested in the motive forces that condition behaviour, specifically the making, the distribution, and the use of artefacts. There is an underlying assumption that every living being acts so as to gratify his own self-interest as he determines that interest to be at any given moment. This is an inevitable by-product of the fundamental concern with cause and effect. Thus such issues as the availability of materials, the demands of patronage, channels of distribution, promotion, available technology, and means of exchange, which require the investigation of external evidence is pertinent. (p. 7)

Although Prown is discussing all of the elements a material culturalist must consider, he outlines the attention to all the facets a designer may challenge within a product in an effort to promote sustainable values as a reflection of cultural ideals. The emphasis on cause and effect implies the responsibility of every decision a designer can make in regards to their work and its ability to promote social change as a consumable product. Prown (1993) recommends researchers use the 
historical causations of craft, culture, and privacy outlined by Peter Gay (1976) in his book Art and Act. He summarizes Gay's work: craft is the traditional way things are done or have been done previously; culture is the prevailing attitudes and beliefs behind why things are done the way they are; and privacy concerns the persons who created the artefact and whether they were conformists or creating an original expression.

Although material culture is the study of something that has already occurred, when applying similar methods to a contemporary product on the fast fashion market, there is an opportunity to challenge the elements of a product for developing a future design. Designers are confronted with a pending decision: will they support the unsustainable values of the garment or strive to create a new set of characteristics and elements that support sustainable initiatives and develop an innovative, alternative product? If material culture is the study of artefacts to understand the values of a society, challenging those values as a sustainable apparel design method could promote new use-values in products and contribute the shift towards a sustainable consumer paradigm. As a designer, there is an opportunity to contribute to social change, as Dant (1999) suggests: “The things we make, appropriate and use are a manifestation of social forms while also shaping them" (p. 12).

Interpretation of belief and value. Prown (1982) argues "The most obvious cultural belief associated with material objects has to do with value" (p. 3). Artefacts can hold more than one value and these values can also change depending on context of the artefact places in the society in which it is found. Appadurai (1986) introduces the concept of things having social lives as a way to comprehend changing value in an artefact. He suggests:

we have to follow the things themselves, for their meanings are inscribed in their forms, their uses, their trajectories. It is only through the analysis of these trajectories that we 
can interpret the human transactions and calculations that enliven things. Thus, even though from a theoretical point of view human actors encode things with significance, from a methodological point of view it is the things-in-motion that illuminate their human and social context. (p. 5)

Kopytoff (1986) suggests creating a biography for an artefact as a means of interpreting material culture. He proposes questioning where an artefact comes from, who made it, what possible career it has, what are the recognized stages of its existence, how does it change in use, and what happens at the end of its life? By following an article through its life, we can determine what kind of value it held for the society or owner during the different phases of its lifecycle.

The most obvious value when considering an artefact as a product deals with production and consumption of the object as a commodity. A commodity is an item that is thought to hold both exchange-value and use-value (Kopytoff, 1986). In terms of a capitalist society, Dant (1999) summarizes Marx's (1976) definitions of these values from Capital: exchange-value is quantifiable in terms of other commodities or money whereas use-value refers to the quality of the object and as it is realized in use (as cited in Dant, 1999, p.45). In regards to fashion products, Rosenblad-Wallin (1985) outlines exchange-value as market based, dealing with the client as buyer, whereas use-value is derived from assessing and fulfilling the functional and symbolic needs or values desired by the client as a user.

Critics of the application of material culture methodologies to fashion scholarship argue that too much emphasis is placed on the fashion article as a product or commodity and that there is not enough investigation into the social relationships that evolve between the object and the wearer. (Dant, 1999; Tranberg Hansen, 2003). Ironically, this is the same critique applied to life cycle analysis with its focus on materials and processes as resources (Fletcher 2012). However, I 
would suggest there is a disconnect between the studies of material culture and sustainable design and the relationship between the two fields of scholarship.

According to Dant (1999), the reflections of use and value in material culture are defined by cultural interactions and appropriations throughout its lifespan and cannot be reduced to economics of exchange. Considering the reciprocal relationship between the clothing, the body, and the sartorial choices made by the wearer, Dant (1999) concludes:

Wearing clothes is a material experience; they are available to be looked at on other people and to be worn by ourselves. Clothes are given meaning in the fashion system by the aesthetics of design, the mechanics of production and the inducements of consumption. But the engagement of the wearer with the garment such that they become part of each other, also gives clothes meaning. (p. 107)

This would imply that fashion has multiple perspectives from which use-value can be approached including, but not limited to, the preconceived concepts of functional and symbolic needs as well as the interactions people have with clothing in a personal and social context. The implications of Dant's research are not incorporated into the work of Tranberg Hansen or Fletcher who suggest material culture does not encompass the relationship and experience users have with garments.

Tranberg Hansen (2003) is a socio-cultural anthropologist, who studied dressing and styling as an expressive process in Zambia. She offers an alternative method for looking at fashion as material culture based on process rather than object. She applies a theory developed by Jonathon Friedman (1991) to fashion. Friedman contradicts Appadurai's (1986) concept of the "social life of things," arguing "Things do not have social lives. Rather, social lives have things (Friedman, 1991, p. 161). Tranberg Hansen concludes within women's fashion practice in 
Zambia, meaning or value is not inherent in the articles of clothing but created through the process of dressing as a means to create an individual look. She suggests garments are chosen for "clothing competence" by the owners in regards to whether fashion items can function as both objects of uniqueness and then evolve into utilitarian function. She examines a society where the value for clothing is based on its ability to express rather than as a possession. Her work encourages designers to examine fashion as process originating with the user rather than focussing on the perceived value of a garment in society.

Fletcher (2012) applies Tranberg Hansen's and Friedman's theories to her own research into use-value, suggesting lifecycle research include the user's experience with a product after purchase rather than focussing on the resources and production of the product. Although Fletcher (2012) did not initiate the research project Local Wisdom to examine the durability of clothing, subsequent analysis of the participants narratives indicated the users' personal interaction, for example the wearing, sharing, altering, and treasuring of their clothes, contributed to the lifespan of the item. Referencing data from the project and additional consumer studies, she concludes that even if a product is designed for both emotional and physical durability and is successful in establishing a bond with the user, it does not necessarily increase use of the garment or stop additional consumption. Although Fletcher (2012) concedes that a garment's design, materials, and production may contribute to the "craft of use" process for increased longevity, her findings appear to dismiss the validity of challenging a fast fashion product to develop an alternative product with the goal of increasing use-value. Her research leads to the question: Why attempt to create an innovative design if longevity is supported by use rather than designed elements embedded in a product? Even Chapman (2005), who advocates for empathetic design, acknowledges while designers might create a product to promote emotional interaction and 
experience, they have no control over or knowledge of the experiences of the user. Laitala and Boks (2012) maintain the hardest phase of the lifecycle to analyse in terms of resources and longevity is the post-purchase phase since everyone maintains their garments in a different manner. However, it is not only garment care that would affect the lifespan of a garment, but the countless ways each user might wear, style, alter, share, manipulate and keep a garment due to their own preferences, economics, skills, and beliefs. Obviously, as Fletcher (2012) indicates, the use phase of a garment's lifecycle is in need of additional research.

I would suggest the research project and findings of Local Wisdom are contingent upon several sustainable values that appear to support the creation of alternative sustainable products. The nine categories of inquiry presented by the project are based on sustainable initiatives and criteria, resulting in narratives predisposed to discuss sustainable values, including durability. Referencing her findings on durability, Fletcher (2012) outlines many of the items presented by the participants had been kept for a long time due to the following practices: "dressing to reflect a personal history, to support self-reliant communities, to defy contested values of a garment producer and to resist cultural pressure to launder" (p. 231). These practices are not characteristics usually reflected or promoted by the producers or the products of fast fashion. The users discuss garment attributes related to sharing, narrative, uniqueness, adaptability, and community. These are all elements that can be considered to be influenced and supported by design decisions relating to the identifiers of use-value.

I would argue: What better way to satisfy consumers' desires for alternative products than by challenging mass produced products with the identifiers of use-value? Niinimäki and Hassi (2011) advocate for a design focus on use-value as a means of promoting longevity as it 
may contribute to a shift in the industry and hopefully satisfy customers to the extent that the production and consumption cycle is altered.

What appears to be missing from the discussion of material culture and concepts of usevalue and longevity is the evidence of the use phase of an object that can be traced and revealed in an artefact. Especially prevalent in garments, due to the nature of fabric and sewing construction, is the evidence of wear and tear and alterations and adaptations made to a garment. In fashion history scholarship, researchers identify and evaluate alterations and adaptations made to the garment, production methods, and materials valued by the owner; adjustments made for fit and restyling; and wear and tear for the frequency of use and maintenance habits in an effort to determine how a garment was worn and used during the use phase of its lifespan (Severa \& Horswill, 1989). The reflection of use in historical garments has implications for use-value design as it may suggest a method of determining evidence of "craft of use" in not only historical but contemporary items of clothing.

Material culture, through its interpretation of artefacts, can determine successful usevalue solutions from historic and contemporary garments that can inform and inspire innovative design solutions for future products.

\section{Methods of Interpretation}

The methods of interpreting an artefact in material culture include several different stages of identification, evaluation, and analysis that can be applied to the process of challenging a fastfashion product found in the contemporary market. Fleming (1974) developed a model for studying artefacts that utilizes a five-step classification of the elements of an artefact that are then analysed by four operations. The five basic properties encompass the facts about an artefact relating to history, material, construction, design, and function. The operations applied to the 
properties are identification, generating a factual description; evaluation, using judgement and comparison; cultural analysis, relating the artefact to its culture; and interpretation, determining the significance of the artefact.

Prown (1982) develops a three consecutive step method from the work of Fleming for interpreting objects that consists of description, based on empirical evidence; deduction, based on empathetic considerations of what it would be like to interact with the artefact; and speculation, where hypothesis and theories are developed for further research and validation. Steele (1998) provides an updated outline to both Prown and Fleming, using her own studies of Victorian dresses and corsets as an example of how material culture interpretation can be applied to historic garments. Severa and Horswill (1989) present a four-stage method for interpreting historical garments as material culture in their article "Costume as Material Culture." Their process is based on the work of Fleming, but is specific to the field of historic garments.

Due to the fact that clothing is worn on the body, Severa and Horswill (1989) suggest interpreting "both the modified body and costume, its modifier, as material culture" (p. 51). Hence they examine the artefact in terms of elements inherent to the item itself and how they evolve based on having been worn on the body and used. Severa and Horswill's method applies the four stages of interpretation suggested by Fleming including identification, evaluation, cultural analysis, and interpretation. Although their method was developed specifically to examine dresses from the 1840 s, they recommend their approach may be adjusted depending on the type of garments and the nature of the information the researcher is attempting to determine from the artefacts. For their research focus, they apply the four stages of interpretation to three elements in regards to the dresses under scrutiny: the materials, design and construction, and workmanship. In regards to materials, they considered fabric source, weave, weight, colours and 
how they were achieved, evidence of wear and tear, selvages, and material quality. For design and construction, they looked at the basic elements creating the structure; for example, the bodice, sleeve, and skirt and how these elements intersected, contemplating fullness, grainline, seamlines, and finishes. Workmanship examines the level of skill, the techniques used to execute the design, and construction choices.

To summarize the methods outlined by Fleming (1974), Prown (1982, 1993), Severa and Horswill (1989), and Steele (1998), and to develop a method suitable to challenging a contemporary product, I have reorganized the process of interpreting an artefact into five stages: description; evaluation; interpretation/challenge; research; and prototyping. Dependent on time, resources, and research requirements, designers decide how detailed, technical, and in-depth each stage of research is needed to support their work.

Description. The first stage of interpreting an artefact or product relies on information collected from the physical properties of the object itself. Fleming indicates this stage includes an orderly, accurate description of the object's five properties including information concerning the date, maker, provenance, condition, and type of construction methods used. The researcher uses both technical tools and methods as well as primary and secondary research to determine any known information about the artefact.

For Prown (1982), his descriptive stage consists of three forms of analysis: substantial, content, and formal. Substantial analysis considers the dimensions, materials, and articulation of the object. Content analysis is related to the object's subject matter and iconology. Prown references decorative designs, motifs, and inscriptions found on the item as possible reflections of content. In fashion or apparel, content analysis could pertain to labels, insignia, images, and emblems found on the garment or what the silhouette or style of the garment might symbolise. 
Finally, to complete the descriptive stage, Prown suggests a formal analysis, similar to that used in art history, to determine elements of line, space, colour, light, texture, and pattern within the object.

Evaluation. The second stage of the interpretation process involves the point of view of the researcher as he/she begins to analyse how the object might have been experienced. Fleming (1974) proposes two stages that could be combined into the evaluation stage: evaluation and cultural analysis. For Fleming the evaluation stage often includes the judgement of quality and comparison to other artefacts in quantifiable terms. During the evaluation stage, several artefacts could be compared to determine what is typical or unusual between the artefacts considering such variables as size, cost, rarity, and differences and similarities found from various regions, time periods, and craftsmen. Steele (1998) proposes that the artefacts might be compared to other types of artefacts depending on the research questions to be answered.

Cultural analysis is related to the relationship the artefact would have to the culture from which it came and encompasses reasons for initial manufacture, how it was intended to be used, and the meanings it communicates with regards to value, status and ideas. Steel (1998) updates and expands on the function of communication of an artefact in fashion suggesting cultural analysis include what the style of the garment tells us about the wearer and what meaning could be inferred by semiotics, the representation of meanings and signs in relation to the culture and context in which the garment is found and which change over time.

Prown (1982) refers to the second stage of interpretation as deduction and suggests three different practices of engagement; sensory, intellectual, and emotional. Data generated during this stage is all based on the researcher's empathetic relationship with the object and the world from which it came. This stage encourages researchers to imagine the object in static and 
operational states with sensory engagement in terms of how it is seen, heard, smelled, and felt. The evaluation stage ties into phenomenological approaches to the object and the experience of the body and its surroundings. Intellectual engagement questions what the function of the object is and how it accomplishes its objective. Emotional engagement is the reaction the researcher has to the object. While Prown admits that an emotional response is subjective, he argues that these responses are generally shared among the population and help the researcher evaluate features from the previous descriptive stage that may have contributed towards the emotional responses experienced by the researcher. Although I would question Prown's suggestion that emotional responses are generally shared, I do believe that the emotional responses of the designer can inform the work that is developed in response to challenging a product.

Severa and Horswill (1989) developed a process of evaluation that is specific to clothing and fashion items. During the evaluation stage, Severa and Horswill suggest examining elements of a garment noting how they have changed. They investigate wear and tear, aging, adding of embellishments, and alterations for fit or style as a reflection of skill, the evolution of use, and how these modifications relate to standards and values of the culture. In essence what they are evaluating is the "craft of use"; evidence of how the garment was used and altered for personal needs and interaction subsequent to the garment's original construction and/or purchase.

With the rise of industrialization, mass production, and globalization, many fashion items are no longer linked with their actual maker but to a brand or manufacturing company (Dant, 1999). This phenomenon raises the question whether material cultural interpretation can apply to contemporary fast fashion garments that have been produced with similar mass manufacturing methods. In spite of the lack of individual craftsmanship evident in contemporary products, Dant concludes: 
Many modern artefacts are made in a very different sort of cultural context from the one in which they are used. In using them we interact with the form of the object, which tells us about functional and aesthetic design, materials technology and manufacturing techniques, in the material culture of origin. These features of the material culture are embedded within the object and released as it is used. (p. 197)

If, according to Dant, using an article releases the values of an object, challenging a fast fashion product would enable a designer to test and use a garment to see what issues arise from the use experience and consider how to change values embedded in homogenized garments. In this regard, the apparel designer has an advantage over the material culturalist during the evaluation stage, since they can literally and physically become the user of the artefact. Unlike historical artefacts, contemporary products do not have to be preserved and conserved, but can be destroyed, if necessary, during the experiential and testing process of evaluation. Challenging a current product enables the apparel designer to use, wear, launder, dismantle, and execute multiple tests and experiments that are not available to the traditional material culturalist looking at historical artefacts. Challenging a product in the fast fashion market is not an exercise in improving elements of a current product but in creating an innovative alternative.

Interpretation/challenge. Fleming (1974), Prown (1982), and Severa and Horswill's (1989) third stage of the method for material culture study creates hypothesis and theories that are based on speculation and interpretation of the data collected from the first two stages of identification and evaluation. Explanations are offered as educated guesses that are corroborated and validated through additional research during the final stage of the material culture method. For historical fashion researchers, the interpretation stage often deals with attempting to date or place the item in history since fashion items often carry no formal inscription or labeling of date. 
Hypotheses developed during this stage often attempt to date an artefact and the consideration of values is used not only to consider cultural beliefs but to place the item in a timeline.

This is the point at which I would argue the methods for challenging a product diverge from the material culture method. During the third stage, a designer would challenge the product in regards to use-value criteria. Walker (2006) believes designers should challenge products on the market in an effort to create more meaningful material culture and suggests using a typology to reveal unsustainable design features.

Incorporating the use-value identifiers outlined in this paper, I constructed a typology that would address the identifiers of use-value with the information generated from the identification and evaluation stages of the use-value challenge method. Within the typology, sustainable and unsustainable practices are recorded that are found within the elements of the garments. Design challenges are generated in response to the values of sustainability found, realizing that some design elements are worth keeping while others need new solutions to promote use-value. Finally, multiple solutions are listed to initiate the research stage of the method and to develop and discover further innovations and improvisation to be tried during the prototyping stage. 
Table 3

Use-Value Typology for Challenging Fast Fashion Products

\begin{tabular}{lcccc}
\hline Use-value identifier & $\begin{array}{c}\text { Sustainable } \\
\text { elements }\end{array}$ & $\begin{array}{c}\text { Unsustainable } \\
\text { elements }\end{array}$ & $\begin{array}{c}\text { Design } \\
\text { challenges }\end{array}$ & $\begin{array}{c}\text { Possible } \\
\text { solutions }\end{array}$ \\
\hline
\end{tabular}

Functional

Expressive

Aesthetic

Physical durability

Emotional durability

Potential durability

Research. The final stage for the material culturalist is to research and validate their findings with other academic fields. Researchers apply their hypotheses and data to other forms of evidence found in various fields of visual culture, sociology, anthropology, history, and popular culture, to validate their findings. This is the stage in which material culture studies becomes interdisciplinary in nature.

Although Prown (1982) suggests the researcher follow these stages consecutively, once the initial analysis is completed and the researcher is in the final validation and research stage he argues that it is pertinent that scholars constantly refer back to the object itself to link evidence and research. Having the garment or fashion product in the studio for constant reference would aid the designer in overcoming the challenges. Through design process, new problems and hurdles arise, and the original, unsustainable product may many offer insight as to how these new design issues may be dealt with. It could also be concluded that the constant referral to an unethically produced garment keeps the designer focused on the task at hand. For the use-value 
apparel designer, this stage is for researching the feasibility of the solutions they developed from their challenge.

Prototyping. The prototyping stage is the point at which the designer applies sustainable initiatives, processes, and solutions that are relevant to the product being created and developed. As mentioned previously, multiple guides suggest different approaches to sustainable design and in other fields there are solutions that are applicable to the medium of fashion. Deciding what solutions are the most appropriate for the project at hand can depend on multiple variables. Best practice is a method for divining what solutions are appropriate, economical, and sustainable for the challenge at hand.

Best practice. In Sustainable Fashion and Textiles: Design Journeys, Fletcher (2008) introduces the concept of best practice in regards to sustainable design: a process for a designer to discover the balance between ethical solutions and creating a satisfying and successful design. This concept is pivotal in the sustainable fashion design process for it encourages the evaluation of options that will affect the final product. Fletcher first presents the concept of best practice with regards to fabric processing methods, outlining that there is no ultimate process or fabric choice, so a designer must contemplate and judge the best option for the design project at hand. She summarizes the challenges to be overcome and lists best practice options as possible solutions. Although Fletcher does not employ the term best practice throughout her book, she returns to the concept of negotiating solutions in other areas of sustainable practice. Fletcher states "Our challenge instead is to build a new vision for fashion that satisfies needs and minimizes poverties" (p. 122). While Fletcher is examining the relationship of participating in fashion versus the social inequities and resources fashion production entails, she is implying the need for balance and scale in future decisions. Fletcher discusses appropriateness as the link 
between the user and the object and whether the resources and energy used in its creation reflect the investment the user will have with the product. The concept of best practice aids a designer in comprehending the multiple variables to consider, including time, feasibility, and economics, before deciding which solution works for the undertaken project.

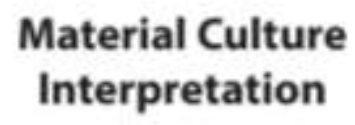

Describe

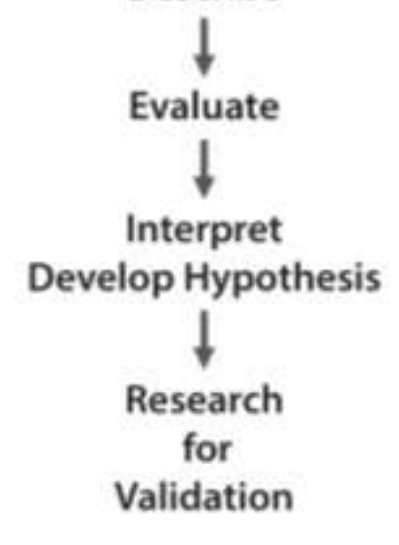

\section{Use-Value \\ Challenge}

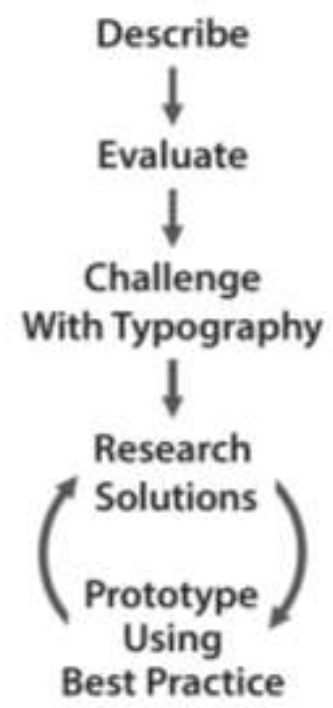

Figure 4. Summary of material culture interpretation and the use-value challenge method.

\section{Process and Perspective of the Use-Value Challenge Method}

One of the benefits of applying a material culture methodology to design work is that it aids us in recognizing our own cultural bias while attempting to keep an objective view of the products we are studying. By analyzing the product through empirical descriptions and imagining ourselves and the artefact in the contexts from which they came, we step outside of our own known culture to examine an alternative culture. Although we can never obtain complete objectivity or experience the artefact in the same reality as the culture from which it came, we can understand similar values and evaluate discrepancies between our own culture and 
the one from which the artefact came, allowing us to determine values of which both contemporary and studied culture may be unaware (Prown, 1982).

However, the concept of applying alternative perspectives to uncover unconscious values in our society does not apply to contemporary product interpretation and challenging since the society in which we live and the one being evaluated is one and the same. In challenging our own products it may be very easy to assume that we comprehend all of the positive and negative values embedded in the product. However, we must find a way to be objective in regards to our unconscious values since Prown (1982) contends that what societies say and do is different from the values reflected in their material culture. We could endeavour to take on an alternative persona or question multiple users to generate objectivity but I would argue a more practical yet objective tool for challenging a contemporary product is the use of a typology. Essentially a typology is a logical organization of types that allows a designer to be thorough and analytical in their research. The stages of description and evaluation from the material culture method can provide incredible amounts of data that can be challenged element by element by the use-value typology to offer a systematic process that will aid the designer in obtaining an impartial and unbiased view of the contemporary products from the world in which they live.

Although a rigorous process, using the steps of material culture studies allows for an indepth reading, interpretation, and subsequent challenge of a product to define its inadequacies, celebrate its positive attributes, and develop an innovative prototype that reflects the values of good design and sustainable initiatives. A case study is presented utilizing the use-value method for apparel design. The case study challenges children's princess costumes found on the fast fashion market with the hopes of creating a sustainable alternative that reflects use-value initiatives. 


\section{Challenging the Fast Fashion Princess}

The market for children's play costumes has grown rapidly in recent years. The princess costume, known for its distinctive silhouette; tight bodice, puffed sleeves, and full gathered skirt, is the most popular style in the realm of children's play costumes. A survey conducted in Brighton, England determined 27\% of available children's costumes were princess-themed, with many of the other genres such as fairy, ballerina, and witch following the same silhouette and fabric choices as the princess style (Pollen, 2011, pp. 165, 169). With the exception of Halloween costume shops, there are three major retailers of children's play costumes in Canada: The Disney Store, Dreampower, and Creative Education Canada. These companies manufacture princess costumes made of synthetic fabrics that have few adaptable or growth functions. It is ironic that for a costume that is supposed to represent the fantasy world of luxury fabrics, discerning taste, high quality and exclusivity, only similar, disposable costumes, lacking in versatility are available. The child of "royalty" today is dressed in polyester and nylon, reflecting the values of the fast fashion market in which the dresses are produced and sold.

Although the wearing of fancy dress by children is not a new phenomenon, play costumes now fulfill multiple functions as toys, film merchandise, party wear, Halloween costumes, and role-playing accessories (Pollen, 2011). Growth in the market has been attributed to The Walt Disney Company and other fantasy franchises that have globalized the industry with their character inspired merchandise and Asian imports (Marshal, 2008; Pollen, 2011). The Disney Princess Brand was introduced in 2000 as a collection of merchandise that was related to the heroines from their animated films. The Disney Princess Brand has generated more than $\$ 4$ billion in worldwide retail sales. ${ }^{1}$ The rise in the children's play costume market has contributed

\footnotetext{
${ }^{1}$ See www.disneyconsumerproducts.com
} 
to the fast fashion dilemma: companies produce inferior, disposable garments to stay competitive. Many of the princess styles offered by Dreampower and Creative Education Canada mimic the characters, styling, and colours of the Disney princess characters, limiting the choice in selection for consumers. In general, play costumes are built from synthetic faux luxury fabrics (polyester chiffons, satins, and velvets) with paste jewels, sequins, spray-on glitter, and vinyl cutouts as decoration. Manufacturing methods rely on construction techniques that rapidly produce costumes that are inferior in durability and quality. Style lines and silhouettes are generic and adaptable size innovations do not offer a refined fit for multiple users or growing children. Regretfully, what is available in the play costume market does not support sustainable initiatives of use-value. 


\section{Chapter Four: Findings and Analysis}

The method for use-value apparel design was applied to three princess costumes, one from each company: Disney Store, Dreampower, and Creative Education Canada. Each dress was analyzed for the description stage (see Appendix A) and evaluation stage (see Appendix B) of the method. The data were combined during the interpretation/challenge stage when the usevalue typology was applied to generate sustainable and unsustainable element, design challenges, and possible solutions. Solutions were researched and the concept of best practice was applied to the viable solutions to aid in the creation of sustainable prototypes. Charts and images were created to help generate and compare data in an easy format.

\section{Description and Evaluation Stages Summary}

The princess dresses follow the traditional princess silhouette of a full gathered skirt with a draped or layered overskirt, puffed sleeves and a fitted bodice. All of these elements are included in a single garment to allow for simple transformation into a princess. The Disney Store and Creative Education Canada dress are full dresses. To accommodate fit and ease in dressing, these dresses use stretch fabrics and utilize an elastic waistband in the construction of their bodices while the Dreampower is a tabard style dress with side openings and no sleeves that is adjustable with ties at the waist. Other than the ties on the tabard style dress, no additional closures are needed. The tabard style by Dreampower is the most accommodating in size. With the sides opened and tied at the waist it could fit a waist of 23 " to 35 " and a chest of 22 " to 34 ".

The Disney Store dress and Creative Education Canada have waistbands gathered on elastic that could accommodate a waist range of 6" or 8" respectively, however the chest on both dresses only have a stretch of 2" allowing only for growth in the belly area. None of the dresses allow for 
an adjustment in length. For the average-size child, the length of the dress hems would all be well off the floor.

Visual interest is created with the use of spray-on glitter, plastic jewels, and metallic trims that are either stitched or glued onto the garment. The Disney Store dress is based on the Disney character of Rapunzel while the Dreampower dress is inspired by the Disney character of Cinderella. The Disney Store dress displays a cameo of Rapunzel sewn to the bodice and a ribbon stitched to one of the hems printed with the slogans from the movie: "Daring to Dream," "A Perfect Princess," and "Always Graceful." The Creative Education Canada dress has reflections of the Disney Store style with a crown appliqué stitched to the front, denoting the symbol of a princess. The Disney Store dress has a decorative lacing detail up the front bodice of the dress and ribbon detail, similar to that of pumpkin hose on the sleeve.

The fabrics of all the dresses are primarily polyester with spandex content for stretch and nylon used for the tulle underskirts. The fabrics are cheap in quality although the Disney Store fabric has custom printed glitter. Both the Disney Store dress and the Creative Education Canada dress fabric has glitter that constantly shed from the dresses. The Disney Store and Creative Education Canada dresses layer fabrics, so that there is a lining against the skin while the tulle layers are encased between the lining and the overskirt, whereas the Dreampower dress have the tulle underskirt open and hanging free. In general the skirt and sleeve fabrics are crunchy and rough to the touch while the bodices use a slippery polyester stretch. The Disney Store dress uses the most variety and volume of fabrics and has the best quality workmanship. All of the edges of the Disney Store garment are encased or bound, compared to the other two garments use cover stitching and serging for most of the finishing and display loose threads and 
fraying ribbons. The Creative Education Canada dress lost the ability for the armholes and sleeve hems to stretch with the application of non-stretch trim onto these areas.

The Disney Store dress was made in China whereas the two other dresses clearly display the fact that they were made in Canada on all tags and labels. Laundry instructions for the dresses when included were: wash in cold, no bleach, and hang dry. Ironing was either not recommended or suggested a heat setting of low. 


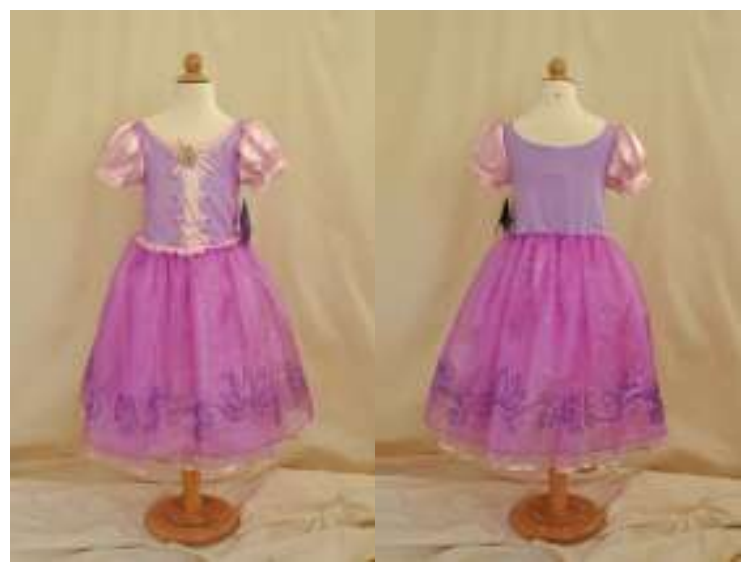

Figure 5. Disney Store Rapunzel princess costume (front and back view).

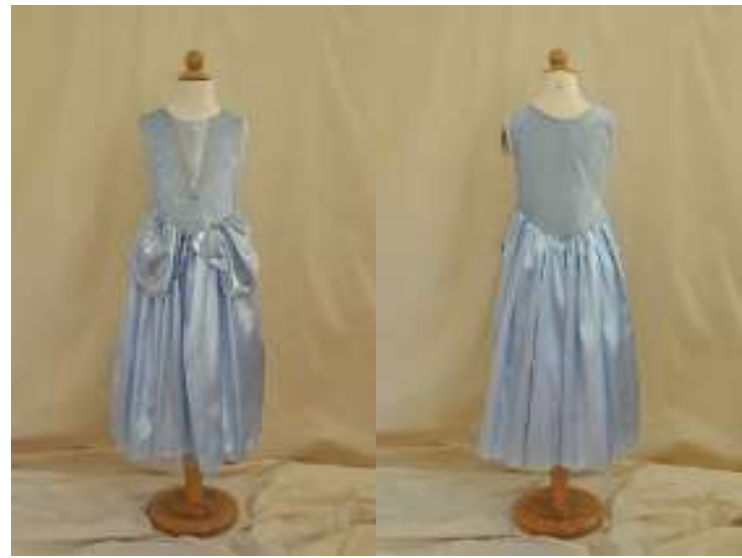

Figure 6. Dreampower Cinderella playtime style (front and back view).

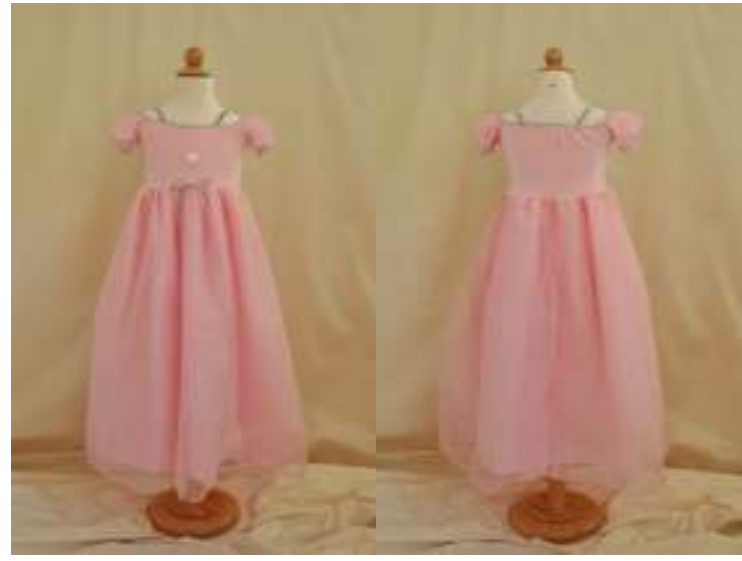

Figure 7. Creative Education Canada princess dress, glitter pink (front and back view). 


\section{Establishing the Challenges from the Application of the Typology}

The typology presented several unsustainable issues that affected multiple identifiers of use-value: lack of imaginative play value; issues with fit and size adaptability; prescribed character inspired styling; and overall quality of materials and finishes. Challenges were explored and solutions were generated based on the issues that arose within the typology to satisfy multiple identifiers of use-value.

The dresses have limited fit adaptability and the potential for adjustment is focused solely on the stomach area of the wearer. Although the dresses depict a general silhouette of a princess, when shared by different users, the size is not adjustable to keep a good fit except by the tabard dress. However the tabard costume has no sleeves therefore does not reflect the complete silhouette of a princess dress. Adaptable waist, chest, and length options are required to accommodate child growth and multiple users.

Costume play is not always a solitary activity but may include several children of various ages and sizes. Children may share costumes and enjoy dressing each other up in different pieces. It was concluded that the more pieces to a costume, the easier it would be to play with multiple users.

The dresses offered very little activity in regards to imaginative play value. The tabard style dress by Dreampower allowed for multiple users, had some adjustment with the ties, and could be easily layered over other garments. The Disney Store dress, with its cameo and printed trim associated the dress to the movie character of Rapunzel and suggested an established story line. It was obvious that animated Disney princesses from their feature films had influenced the designs and colours of the other dresses, limiting options on the market for other inspirations and options for princess role play. Further research online confirmed that the majority of princess 
dresses were inspired by the colours and characters of Disney princesses. The Dreampower website $^{2}$ promoted 13 princess style dresses, six of which reflected Disney princess attributes while the Creative Education Canada website ${ }^{3}$ offered a larger range of princess and queen dresses with alternative themes from history and literature with only three of twelve dresses inspired directly from Disney characters. "Child development scholars have noted the potential of modern, mass-produced amusements to `script` and restrict imaginative play (Paoletti, 2012, p. 133). Ideally, a princess dress should encourage a child to take an imaginative leap, transporting her from everyday existence into a world of fantasy. Donning a costume should stimulate role play and story development based on a child's own imagination or historical, mythical, or fairy-tale inspirations of the child's own choosing rather than the prefabricated personalities established by Disney. The costume should hold and stimulate the interest of a child for years of expressive play. The requirement for transformation and imaginative play value suggests versatility as a function for the costume as well as creative inspiration not related to existing movies, fairy tales, or stories for the theme of the dresses.

Although shiny, sparkly, and likely attractive to a young child, the fabrics were found to be cheap in quality, tacky in choice, and shed glitter profusely. A higher quality of fabric, denoting the status of a princess, was desired. Surface design, embellishment, and trims would need to be fancy yet durable.

\section{Generating and Researching Use-Value Solutions}

The design challenge for a successful princess dress would include multiple components and adaptable styling for expressive play. Using historical fashions as inspiration for silhouette

\footnotetext{
${ }^{2}$ See www.dreampowercostumes.com

${ }^{3}$ See www.creative-edu.com
} 
and style lines, the princess dress would be based on a modular design with several components that could be interchanged to present various looks, characters, or scenarios for the wearer. Possible components might include variable sleeves, overskirts, adjustable skirt shapes, and historical accessories such as hoop skirts, panniers, and bustles to alter the silhouette. A modular design would support the need for versatility and transformation while adding use-value to the costume.

On occasion, several children of various sizes may play simultaneously with the costume, and the option to easily adjust size and close fit would be ideal. A system of fasteners and rigging could be developed to accommodate adjustable closures and adaptable structures. These innovations would allow for waist, chest, and length variables for fit while also allowing the garments to reflect different fits, looks, and characters. Snaps, buttons, magnets, and lacing were all considered as acceptable fastening and closure systems for the modular and adjustable components of the princess costume, although the environmental impact of the additional notions would have to be investigated.

Canadian flowers were chosen as inspiration for the line to create a general concept for the dresses that might encourage storytelling and role playing. Local design and local flowers could be used as future promotional or marketing ideas linking the flowers to Canadian geography, history, and heritage as avenues for increasing engagement with the costume without limiting imaginative play options. 
Table 4

Typology for Challenging a Fast Fashion Princess

\begin{tabular}{|c|c|c|c|c|}
\hline $\begin{array}{l}\text { Identifiers } \\
\text { of use- } \\
\text { value }\end{array}$ & Sustainable elements & Unsustainable elements & Design challenges & Possible solutions \\
\hline Function & $\begin{array}{l}\text { - stretch fabrics } \\
\text { allow for easy } \\
\text { donning and } \\
\text { doffing } \\
\text { - stretch fabrics } \\
\text { allow for general } \\
\text { shape of princess } \\
\text { dress }\end{array}$ & $\begin{array}{l}\text { - waist only expansion } \\
\text { - no adjustable fitting } \\
\text { except for pinafore style } \\
\text { - some fabrics were } \\
\text { scratchy or had no lining } \\
\text { between tulle and body } \\
\text { - no imaginative play } \\
\text { value or alternative } \\
\text { styling }\end{array}$ & $\begin{array}{l}\text { - create a dress with } \\
\text { adaptable fit for } \\
\text { growth in waist, } \\
\text { chest, and length, } \\
\text { - find alternative } \\
\text { fabric, softer } \\
\text { - create imaginative } \\
\text { play value }\end{array}$ & $\begin{array}{l}\text { - kids' clothing for } \\
\text { growth options } \\
\text { - reuse silk from } \\
\text { second hand wedding } \\
\text { dresses } \\
\text { - historical options for } \\
\text { modular design }\end{array}$ \\
\hline Expression & $\begin{array}{l}\text { - keep general } \\
\text { princess shape on } \\
\text { body }\end{array}$ & $\begin{array}{l}\text { - focus on branded } \\
\text { characters limits } \\
\text { imaginative play value } \\
\text { - cheap polyesters do not } \\
\text { denote luxury }\end{array}$ & $\begin{array}{l}\text { - alternative } \\
\text { inspiration for theme } \\
\text { - alternative fabric } \\
\text { choice for luxury } \\
\text { - keep traditional } \\
\text { princess silhouette }\end{array}$ & $\begin{array}{l}\text { - source creative } \\
\text { inspiration for line } \\
\text { - reuse silk from } \\
\text { second hand wedding } \\
\text { dresses } \\
\text { - use dead stock for trim }\end{array}$ \\
\hline Aesthetics & $\begin{array}{l}\text { - keep general } \\
\text { princess shape on } \\
\text { body } \\
\text { - multiple textures } \\
\text { for delineation of } \\
\text { parts }\end{array}$ & $\begin{array}{l}\text { - glitter falls off } \\
\text { - tacky fabrics }\end{array}$ & $\begin{array}{l}\text { - find decorative } \\
\text { surface that is } \\
\text { attractive yet } \\
\text { durable } \\
\text { - keep traditional } \\
\text { princess silhouette }\end{array}$ & $\begin{array}{l}\text { - dye second hand } \\
\text { wedding dresses for } \\
\text { alternative colour } \\
\text { choices and surface } \\
\text { design }\end{array}$ \\
\hline $\begin{array}{l}\text { Physical } \\
\text { durability }\end{array}$ & $\begin{array}{l}\text { - polyester is easy to } \\
\text { launder }\end{array}$ & $\begin{array}{l}\text { - glitter comes off easily } \\
\text { - lots of narrow serged } \\
\text { edges to get caught on } \\
\text { things, will not launder } \\
\text { well }\end{array}$ & $\begin{array}{l}\text { - find decorative } \\
\text { surface that is } \\
\text { attractive yet } \\
\text { durable } \\
\text { - find washable } \\
\text { fabrics, kids are } \\
\text { messy }\end{array}$ & $\begin{array}{l}\text { - dye second hand } \\
\text { wedding dresses for } \\
\text { alternative colour } \\
\text { choices and surface } \\
\text { design }\end{array}$ \\
\hline $\begin{array}{l}\text { Emotional } \\
\text { durability }\end{array}$ & $\begin{array}{l}\text { - tie to branded } \\
\text { character, } \\
\text { establishes a } \\
\text { relationship }\end{array}$ & $\begin{array}{l}\text { - no imaginative play } \\
\text { value }\end{array}$ & $\begin{array}{l}\text { - how to create } \\
\text { interaction, narrative }\end{array}$ & $\begin{array}{l}\text { - modular } \\
\text { - alternative styling } \\
\text { - link to inspiration } \\
\text { - locally sourced } \\
\quad \text { materials and } \\
\quad \text { processes }\end{array}$ \\
\hline $\begin{array}{l}\text { Potential } \\
\text { durability }\end{array}$ & $\begin{array}{l}\text { - has side ribbons for } \\
\text { easy sharing and } \\
\text { growth }\end{array}$ & $\begin{array}{l}\text { - limited sharing } \\
\text { capabilities } \\
\text { - limited physical } \\
\text { durability }\end{array}$ & $\begin{array}{l}\text { - how to encourage } \\
\text { self-styling } \\
\text { - create a garment that } \\
\text { can be shared } \\
\text { - consider quality in } \\
\text { material and } \\
\text { construction }\end{array}$ & $\begin{array}{l}\text { - modular designs } \\
\text { - alternative styling } \\
\text { - source new fabrics } \\
\text { - make adaptable in } \\
\quad \text { size }\end{array}$ \\
\hline
\end{tabular}




\section{Prototype Design Development}

Data and inspiration from historical sources and current children's product information was collected into a design journal. Design ideation development focused on creating a modular costume system with versatile styling. With the use of sketches and brainstorming, the traditional princess dress was exploded into multiple pieces and sketched as individual components.

During a previous study, fabric sourcing and finishing techniques were researched and developed. Repurposed silk wedding dresses were sourced as the primary fabric, supplying tulle, silk, and decoration. Dye tests were undertaken to determine the feasibility of dying silk dresses with the least toxic process available with resources at hand. Although flavoured drink powder was initially thought to be a viable dyestuff, it was limiting in colour range. Acid dye was subsequently used for its bright colours, colour fastness, and laundering possibilities. Acid dye allowed for several tones to be achieved in the same colour by using the same dye bath until all of the dye had been exhausted. Dye tests resulted in a rainbow of colours and created a variety of visual interest depending on the fibre content of embroidered fabric and laces. Dye was absorbed at different rates creating contrasting texture and patterns on the fabric. The woven silk did however present a donning and doffing challenge, creating the need for closures due to the rigidity of the fabric.

The dresses were constructed with quality notions, fabrics, and construction methods. Seams were enclosed or finished in such a manner that they would not be destroyed by the use of hook and loop fasteners on the costume. Although a rolled serge hem was used for some hem finishes, tests were executed to discover at what density and size the rolled hem finish had to be executed for durable wear and tear. 


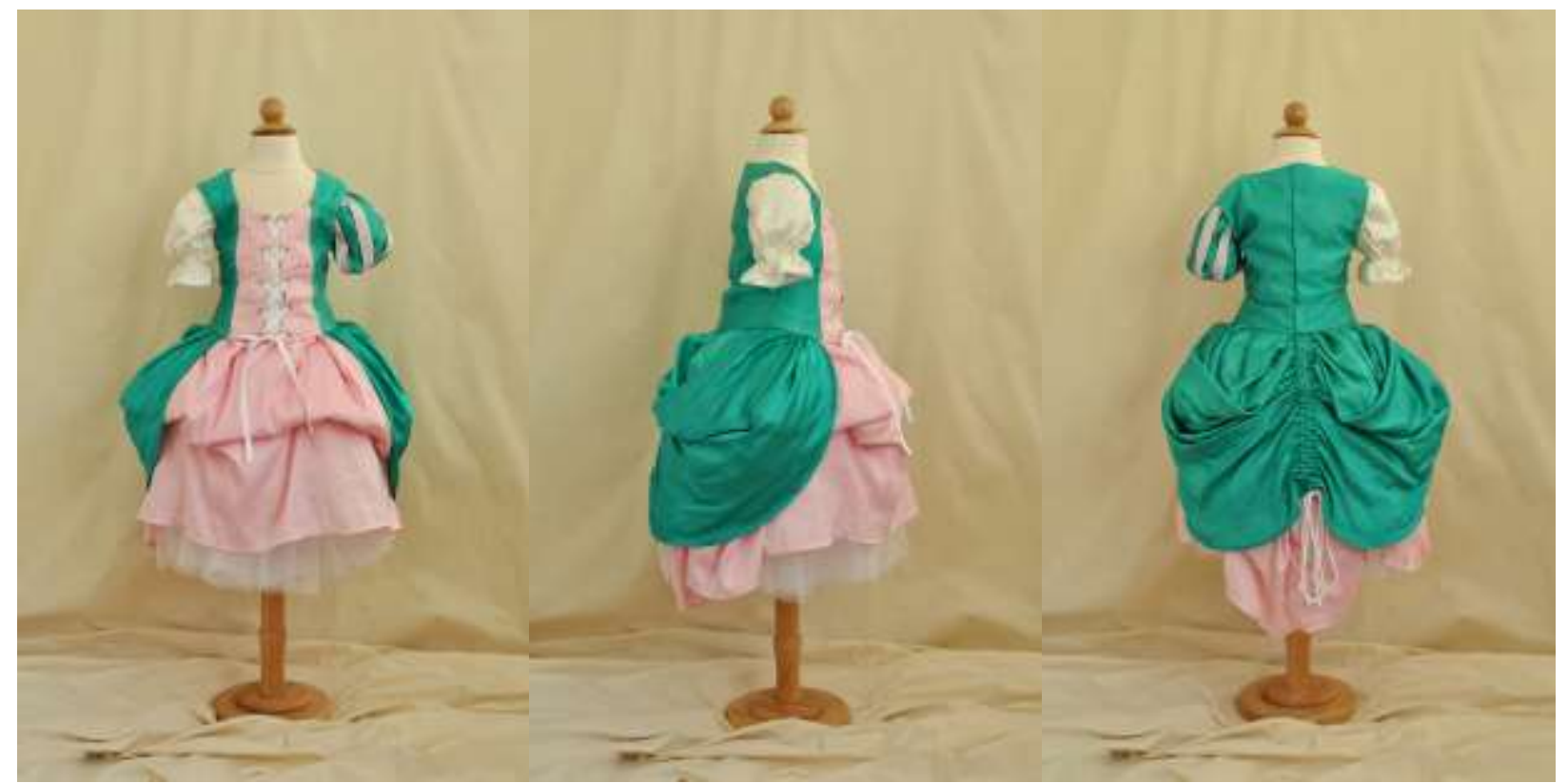

Figure 8. Pink Tulip princess costume prototype. Displayed on a size 3-4 judy with skirt worn short (front, side, and back view).

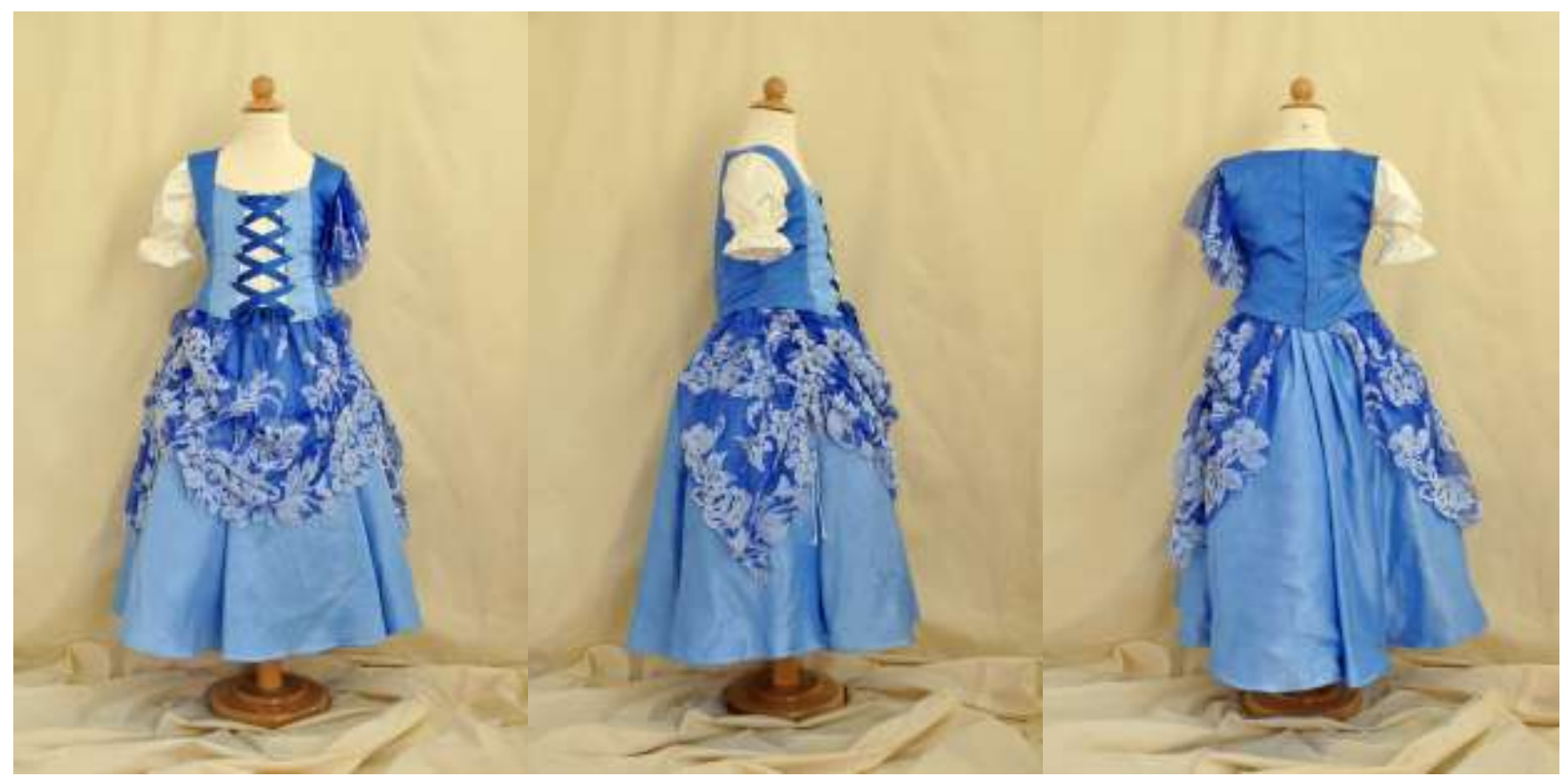

Figure 9. Blue Iris princess costume prototype. Displayed on size 6-8 judy with skirt worn long (front, side, and back view) 
Underskirt. Tulle and lining, cut from the underskirt of an existing wedding dress, was gathered into an elastic waistband to create the underskirt. Worn as a foundation garment, the underskirt creates the shape for the required silhouette. The elasticized waist allows for easy donning and doffing and the accommodation of various waist sizes within a range of 8 ".

Skirt. Using silk cut from a wedding dress, the skirt was created by gathering the fabric onto a waistband. A hook and loop closure was created on the waistband to accommodate a 5" change in circumference from 22" to 27 '. Inside the skirt four sets of twill tabs were stitched to allow the hem of the skirt to rise 10 " from 28 " to 18 ". Not only does this design innovation allow the hem to adjust in height, it also provides alternative styling.

Overskirt. The overskirt is a versatile, decorative layer. It consists of a shaped skirt on a pleated waistband with a gathering mechanism built into the seams. The overskirt can be worn either straight or gathered in a variety of draped looks while also accommodating the need for different hem lengths.

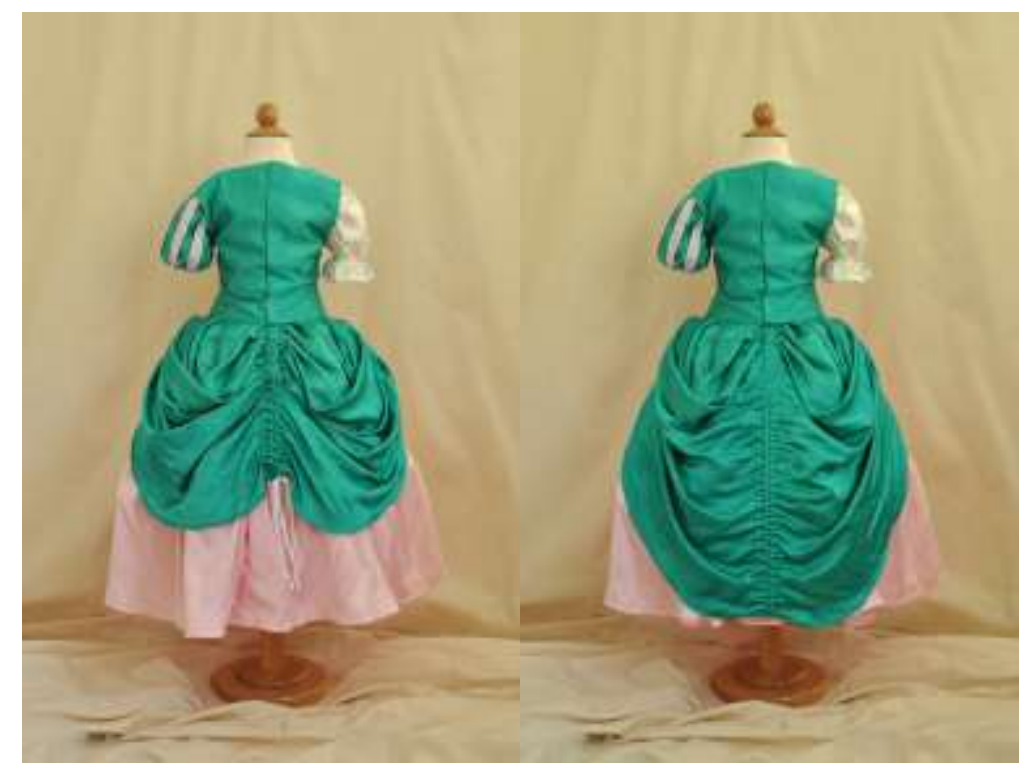

Figure 10. Pink Tulip prototype overskirt options (displayed gathered up and released down). 


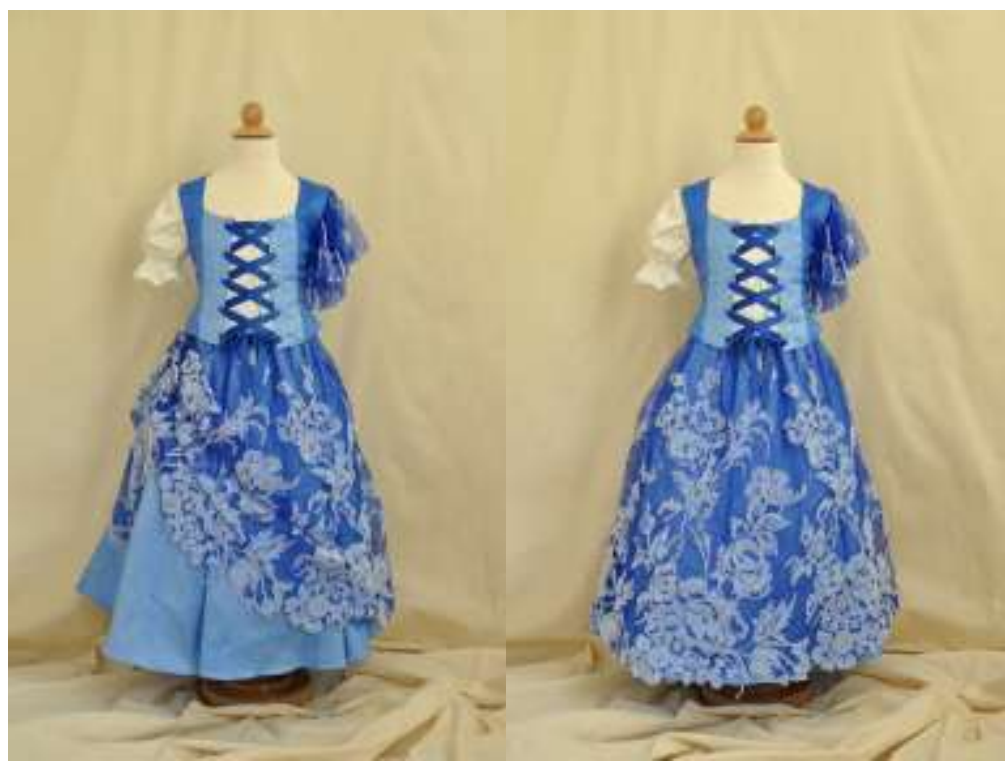

Figure 11. Blue Iris prototype overskirt options (displayed with one side gathered up and both sides released down).

Bodice. Based on a historical laced corset style, the bodice consists of the matching fabrics to link the modular components visually. The bodice has a center back hook and loop closure to accommodate ease in donning and doffing, and a grommet and laced front detail. A white placket, representing a chemise, stitched behind the grommets allows the lacing on the bodice to expand 5" from 22 " to 27 " in breadth while also providing a decorative detail. The bodice is drafted in such a way that it should be able to accommodate several sizes of children, with the waist sitting at different places on the body and still attractive in fit. Magnets were stitched under the straps of the bodice to allow for modular units to be snapped into place for a sleeved version of the costume.

Sleeves. Three different styles of sleeves were designed to test the versatility of the modular bodice design. A puffed sleeve similar to one found on a historical chemise was created to match the placket on the bodice. A ruffled sleeve was designed to utilize lacy fabrics found in the overskirts. A historical slashed sleeve style was designed to tie in colours found in the skirt 
and bodice of the dress. Magnets corresponding to the bodice were stitched at the edge of the sleeve for easy insertion under the straps of the bodice.

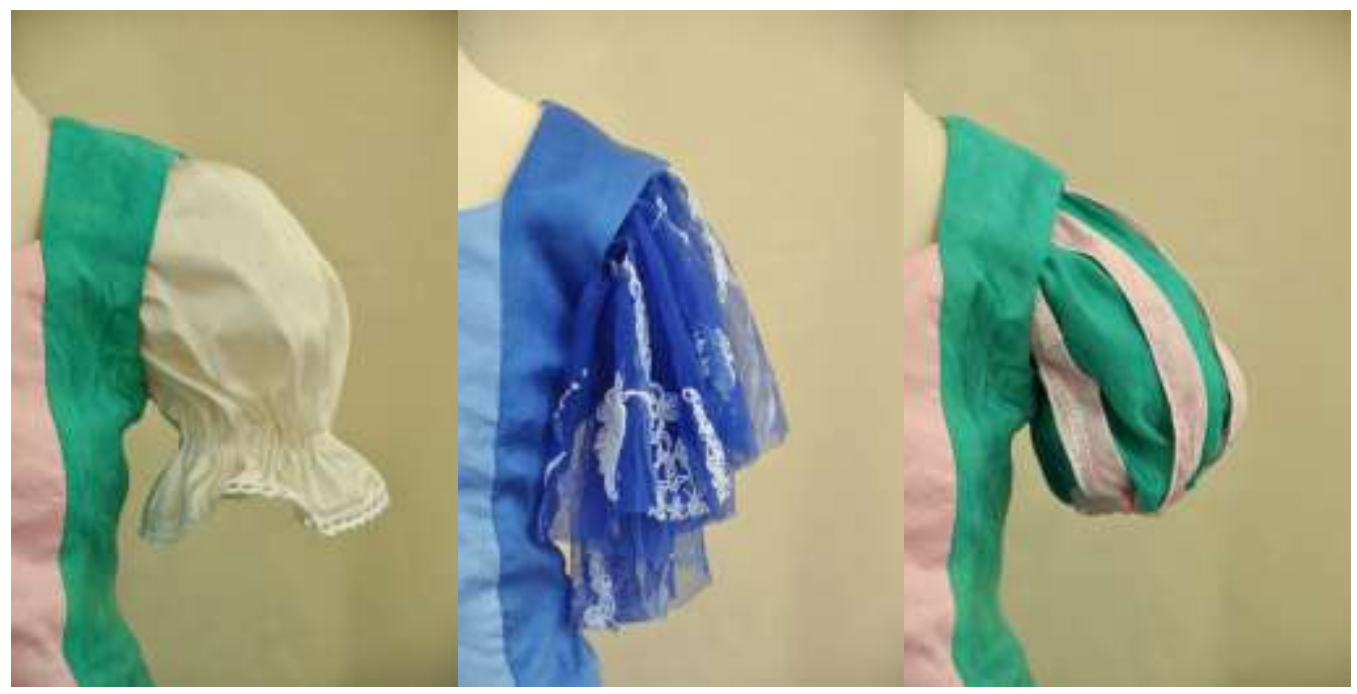

Figure 12. Three modular sleeve options (puffed, ruffled, and slashed).

\section{Results}

Flowers were used as the creative inspiration for the prototypes, providing an alternative aesthetic and mode of expression to the character inspired merchandise currently on the market. Second-hand silk wedding dresses were sourced and dyed to provide the material for the prototypes, decreasing the need for new resources. The dye process created a varied and embellished surface texture for the costumes, producing brightly coloured components that are easy to wash and will age gracefully.

The challenged fast-fashion princess dress was dissected into various components that inspired a modular system for the alternative prototype consisting of an under-skirt, skirt and decorative overskirt, bodice, and removable sleeves to encourage imaginative play value and provide multiple styles with one costume. The skirts were designed with not only an adjustable waistband, but with pulleys and ties that allow for variable styling and hem lengths. Bodices incorporated front lacing, which allow for an additional 5" in fit. These innovations kept the 
traditional silhouette of the princess dress while providing for adjustable sizing for growth and multiple users. The design process indicated the techniques and hardware that support multiple styling; for example, ribbons, pulleys, cords, buttons, and loops, become part of the aesthetic and expression of the garment. A variety of closures provide a positive opportunity for development of fine motor skills.

Although overwhelming at times, applying the use-value typology to the elements of the fast fashion princess dresses generated multiple viable solutions. Applying the concept of best practice to these solutions not only determined the best options for the current prototype but generated design inspirations for additional prototypes. Due to time restraints, within this phase of prototyping I had no opportunity to research sustainable and ethical sourcing of magnets, grommets, and zippers. Although I used these elements on the current design, the process of best practice led me to additional design scenarios for the future: research alternative and sustainable closures or develop yet another prototype that utilizes no plastic or metal notions within the design.

Imaginative play value and user experience was promoted in the alternative design by the various components that allowed for changes in style, fit, and size. The design of the prototype does not limit role playing to a prescribed character from a movie but allows for exploration and experimentation with the garment. The colours and embellishment do not refer to a specific market character and the modularity and adjustable styling encourage story telling that could be related to the different looks and configurations created by the child playing with the costume. Although, at this juncture, there is no way of knowing the success of the design, the prototype allows for children to create their own looks, styling and choice of fit, encouraging the concept of "craft of use" and satisfying the criteria for potential durability. 


\section{Chapter Six: Discussion}

The limitations of this research are related to the scope and size of the study. The usevalue method for apparel design was only applied to one style of garment. Although three individual princess costumes were interpreted and challenged, only one round of prototyping was executed in response to the fast fashion challenge. In-depth testing of materials was not applied during the challenging or prototyping stages to generate scientific data with regards to the sustainability of the materials and finishes used.

At present there is no way of comprehending the success of the alternative prototype. It has not been field tested, nor is there any mechanism for testing emotional and/or potential durability. One avenue for future research would be to find a way to integrate the framework into a participatory design for testing and feedback. Ideally feedback programs would encourage clients to share their narrative of how a product was used and allow the examination and evaluation of the garment either during or at the end of its lifespan.

Although further trials are needed to support the validity of the use-value method for apparel design, the case study indicates that challenging a product from the fast fashion market is a viable method for sustainable garment design. Unlike current sustainable apparel design literature that presents multiple solutions with broad applications, the use-value method for apparel design generates solutions that are specific to the garment being created. What is missing in current sustainable fashion design literature is a method for analysing and applying multiple sustainable criteria to an individual design project. The use-value method for apparel design is systematic and analytical, allowing designers to dissect a product and consider all the elements in terms of sustainability. The method encourages evaluation from the perspective of the user; a 
process that satisfies not only the perceived needs of the user but the potential future needs that may develop during the use-phase of the garment's lifespan.

Within the use-value method for apparel design, the systematic and detailed stages developed from material culture methodology generate information about design, materials and construction that designers might otherwise overlook in the design process. The obvious conclusion would be that the only negative attributes would be discovered during the third stage of the method that challenges the garment by applying the use-value typology. However, both sustainable and unsustainable characteristics were determined during the challenge stage of the method that led to viable solutions for the alternative prototype.

Although this was my third phase of prototyping with the princess dress concept, I was surprised by attributes of the challenged fast fashion princess dresses. The interpretive process presented the fast-fashion princess costume not as a problem to be solved, but as a resource for creative inspiration, as it revealed elements that either promote or impede use-value.

The quality of workmanship and finishing in the princess dress manufactured by the Disney Store exceeded my expectations. Although the price point of the dress was notably higher than that of the Dreampower and Creative Education Canada costumes, I had wrongly assumed that the price reflected the branded attributes of the costumes and not the quality. The finishing techniques of the Disney Store dress informed my design decisions on how to layer the skirts, hide seams within the bodice, and finish seams and hems.

The extent to which Disney, with their character inspired merchandise, has influenced the expression and aesthetics of princess costumes is much greater than I first realized. I found that the character inspired merchandising of Disney limited both consumers and designers with regards to choice and expression. Consumers have limited choice in colour and styles of princess 
costumes because companies, in an effort to compete with product offerings, reflect the same characters, colours, and styles as Disney in their product lines (see Appendix C). The colours and styles dictated by the Disney character inspired costumes force designers from other companies to acknowledge colours and styles and their relationship to characters. For example, blue represents Cinderella whereas yellow refers to Belle from Beauty and the Beast. Designers can either accept these limitations and work within the Disney genre of princesses or be aware of colour and style character associations and strive to create unique princess costumes.

The imaginative play of a child is limited by the character inspired merchandise, since the Disney Store costume clearly denotes both the physical and aspirational characteristics of the princess associated with a specific costume. The Disney Store princess costume displays a cameo of the cartoon princess associated with the costume and slogans from the movie are imprinted on the dress. Children playing with Disney inspired costumes may feel restricted to the story line denoted by the prescribed character and be intimidated to portray their own concept of character. The animated character inspired costume could also affect the emotional durability of the garment for when the trend or desire for that character fades, or children are bored of playing that particular role, their attachment to the costume might diminish. The character inspired Disney princess costumes motivated me to develop a costume without a storyline. Inspired by natural flowers, with multiple looks and adaptations, the alternative princess costume might encourage children to role play characters of their own choosing without limiting the princess costume to one prescribed character.

Without comparing multiple products with the interpretive lens of material culture, I would have overlooked the branding initiatives of Disney and the reflection of similar trends with other producers of princess costumes. Ironically, Disney has set the bar rather high for 
alternative princess costumes, since their own dresses are of a high quality construction, albeit made of synthetic fabrics. They also have multiple princess characters, which are incredibly popular due to their vast marketing enterprise, from which to choose. Due to the copycat nature of companies to replicate inferior, cheaper versions of popular styles and the restrictions branding may place on design innovations and creativity, I would suggest more research is needed with regards to the relationship between branding and sustainable apparel design.

The concept of experiencing a garment as a user was significant in generating solutions that addressed the identifiers of use-value dealing with durability and expanding the lifespan of a garment. Imagining myself as the user and referring to my own experience as an apparel designer, I hypothesized about how a garment could be used in the future and what elements might lead to its possible disposal. I attempted to evaluate what features would lead to promote more user experience and interaction with the costume. I discovered the concept of experiencing the product worked not only for the challenged garment, but for the newly created prototypes as a way of testing the garment with regards to the use-phase.

While the specifics of how a user might experience, interact and use a garment in the future are unknown, emotional and potential durability can be considered during design process. Placing myself in the context of the user, a child playing with the costume, the idea of having multiple pieces to play with and the ability to alter and change those pieces to become different characters, informed my design inspirations for imaginative play value that would hopefully lead to emotional durability of the costume. Potential durability, the term I propose for promoting future use, can be imagined by designers. Although altering and sewing skills are suggested for the "craft of use" (Fletcher, 2012) and design services for future use (Niinimäki \& Hassi, 2011), children do not possess the ability to apply these future applications to a garment. The fact that 
children would be wearing the princess dresses created the need for re-styling mechanisms that do not require sewing or extrinsic services. Since the costume was for a young child, I attempted to use closures and adaptable features that they would be able to manipulate easily. I used magnets for the sleeve design for easy switching of styles, hook and loop fasteners for easy doffing and donning, and pulleys and ties for adjusting the skirts. These design elements would support potential durability as the costume can be manipulated for different contexts of play and changed to present multiple looks while lasting for years of sharing with additional users. The use-value method for apparel design is successful at contemplating the elements of potential durability and embedding possible future use into a garment.

The use-value method for apparel design can be utilised as an educational tool or as a creative process for designers working in the niche market of sustainable design. The method offers avenues of exploration and prototyping in use-value design that are feasible and achievable for the fashion designer. Vast resources are not needed to implement the method and it is accessible to designers no matter what their level of experience. Although the proposed method for challenging a product can be used as an exercise in creating an alternative garment, I discovered that as the research process evolved, the method began to influence my overall design philosophy rather than just the garment I was challenging. The use-value method for apparel design could ideally be integrated into the fashion design process to automatically promote sustainability rather than being categorized as a specific method for sustainable design.

The relationship between material culture and sustainable design has yet to be fully explored. Material culture has the potential to provide sustainable solutions from historical artefacts, revealing attributes that have promoted use-value and longevity in the past. The interpretative methods of material culture provide an analytical tool for tracing wear and tear, 
alterations, and adaptations to evaluate what elements and attributes affect use-value in garments. Ultimately material culture interpretation can provide innovations and inspiration for future designs.

Material culture, with its focus on the product as artefact, allows sustainability to be an achievable goal for the designer and hopefully for the consumer as well. "Material possessions are used as symbols of what we are, what we have been and what we are attempting to become" (Schultz, Kleine, \& Kernan, 1989). The methods of material culture interpretation, which are largely historical or anthropological, can be adjusted for challenging a product on the contemporary fast fashion market. The proposed use-value method for apparel design offers designers a process for challenging a garment from the fast fashion market to generate use-value solutions for an alternative product for the future. Challenging a product on the fashion market is not an exercise in making a product better but creating an alternative garment and offering solutions that the designer and consumer may not yet be aware of. Products that are embedded with use-value may prolong the experience and engagement of the user, promoting a longer lifespan of the garment, while slowing the cycle of consumption. Challenging a product to increase use-value offers the designer an achievable method to develop meaningful, sustainable material culture. 


\section{Appendix A: Description Stage of Use-Value Method}

\begin{tabular}{|c|c|c|c|}
\hline Description & Disney & Dreampower & $\begin{array}{c}\text { Creative Education } \\
\text { Canada }\end{array}$ \\
\hline Size & $7 / 8$ & $7-9$ & Medium 5-6 \\
\hline $\begin{array}{l}\text { Overall length (nape to } \\
\text { hem) }\end{array}$ & $33 ”$ & $39 "$ & $351 / 2 "$ \\
\hline Bodice length & $71 / 2 "$ & $71 / 2 "$ & $6 "$ \\
\hline Skirt Length & 21 & $28 ”$ & $26 "$ \\
\hline Waist Measurement & $26 "-32 "$ & $23 "-35 "$ & $28 "-36 "$ \\
\hline Chest measurement & $26 "-28 "$ & $22 "-34 "$ & $26 "-28 "$ \\
\hline Closures & none & Ties at both side waists & None \\
\hline Style Name & Rapunzel & Playtime Cinderella & $\begin{array}{l}\text { Dress Princess Glitter } \\
\text { PK }\end{array}$ \\
\hline Hang Tag Information & - safety & $\begin{array}{l}\text { "Dream Power since } \\
1988 " \\
\text { - safety }\end{array}$ & $\begin{array}{l}\text { "Made in Canada" Leaf } \\
\text { Label } \\
\text { "Great Pretenders } \\
\text { Creative Education } \\
\text { Canada" } \\
\text { "3+" } \\
\text { - safety }\end{array}$ \\
\hline Laundry Instructions & $\begin{array}{l}\text { "HANDWASH COLD } \\
\text { SEPARATELY. ONLY } \\
\text { NON-CHLORINE } \\
\text { BLEACH, WHEN } \\
\text { NEEDED. LINE DRY. } \\
\text { DO NOT IRON." }\end{array}$ & - none & $\begin{array}{l}\text { "Machine Wash - Cold, } \\
\text { Gentle Cycle, No } \\
\text { Bleach, Drip Dry, Low } \\
\text { Iron" }\end{array}$ \\
\hline Safety Instructions & $\begin{array}{l}\text { "Choking hazard may } \\
\text { contain small part. Not } \\
\text { for children under the } \\
\text { age of 3." } \\
\text { "Caution: During } \\
\text { handling and play this } \\
\text { garment may release } \\
\text { particles of glitter." }\end{array}$ & - none & $\begin{array}{l}\text { "Keep away from fire." } \\
\text { "Not suitable for } \\
\text { children under } 36 \\
\text { months due to small } \\
\text { parts CHOKING } \\
\text { HAZARD!" }\end{array}$ \\
\hline "Made in" & China & Handmade in Canada & Point Edward Canada \\
\hline
\end{tabular}




\begin{tabular}{|c|c|c|c|}
\hline Description & Disney & Dreampower & $\begin{array}{c}\text { Creative Education } \\
\text { Canada }\end{array}$ \\
\hline Main Colour & Pink & Light Blue & Pink \\
\hline \multicolumn{4}{|l|}{ Sleeve Elements } \\
\hline Materials & $\begin{array}{l}\text { - } 100 \% \text { polyester } \\
\text { - pink satin liner } \\
\text { - pink layer with spray } \\
\text { on sparkle chiffon }\end{array}$ & $\mathrm{n} / \mathrm{a}$ & $\begin{array}{l}\text { - sleeve }-92 \% \\
\text { polyester, } 8 \% \text { Spandex } \\
\text { pink stretch velvet } \\
\text {-gathered Overlay - } 100 \\
\% \text { polyester net with } \\
\text { spray on glitter }\end{array}$ \\
\hline Style & - puff sleeve & - sleeveless & $\begin{array}{l}\text {-off the shoulder puff } \\
\text { with } 1 / 4 " \text { silver elastic } \\
\text { spaghetti straps }\end{array}$ \\
\hline Embellishment & $\begin{array}{l}\text { - pink 1" ribbons edged } \\
\text { in gold, from sleeve } \\
\text { head to cuff, pumpkin } \\
\text { hose style } \\
\text { - 1/2" pink ribbon trim at } \\
\text { hem } \\
\text { - light pink scallop lace } \\
\text { trim at hem }\end{array}$ & $\mathrm{n} / \mathrm{a}$ & $\begin{array}{l}\text { - silver double loop } \\
\text { braid at hem }\end{array}$ \\
\hline Decorative motifs & - none & $\mathrm{n} / \mathrm{a}$ & - none \\
\hline Finishing & $\begin{array}{l}\text { - bias binding at hem } \\
\text { and sleeve-head. } \\
\text {-seam serged. }\end{array}$ & $\mathrm{n} / \mathrm{a}$ & $\begin{array}{l}\text {-cover stitch at hem } \\
\text { - cover stitch at shoulder } \\
\text { - due to stitched trim, no } \\
\text { stretch at sleeve hem }\end{array}$ \\
\hline \multicolumn{4}{|l|}{ Bodice Elements } \\
\hline Materials & $\begin{array}{l}\text { - back polyester stretch } \\
\text { - Front- layered } \\
\text { polyester } \\
-1^{\text {st }} \text { - lining and chiffon } \\
\text { sprayed with sparkle } \\
-2^{\text {nd }}-\text { bodice sequined } \\
\text { fabric and layer of } \\
\text { darker pink chiffon }\end{array}$ & $\begin{array}{l}\text { - polyester, light blue } \\
\text { stretch velvet }\end{array}$ & $\begin{array}{l}\text { - bodice } 92 \% \text { polyester, } \\
8 \% \text { spandex, pink } \\
\text { stretch velvet }\end{array}$ \\
\hline
\end{tabular}




\begin{tabular}{|c|c|c|c|}
\hline Description & Disney & Dreampower & $\begin{array}{c}\text { Creative Education } \\
\text { Canada }\end{array}$ \\
\hline Style & $\begin{array}{l}\text { - fake lace front, stretch } \\
\text { back } \\
\text { - straight waistline }\end{array}$ & $\begin{array}{l}\text { - pinafore style, dropped } \\
\text { waist } \\
\text { - yoke style waist } \\
\text { - same front and back }\end{array}$ & $\begin{array}{l}\text { - boat neck } \\
\text { - straight waistline } \\
\text { - same cut front and } \\
\text { back }\end{array}$ \\
\hline Embellishment & $\begin{array}{l}\text { - non-functioning front } \\
\text { lacing, pink ribbon } \\
\text { lacing, light pink scallop } \\
\text { lace on neckline } \\
\text { - eyelets for lacing } \\
\text { bound in metallic pink } \\
\text { thread } \\
\text { - 1/4" Ribbon for lacing } \\
\text { light pink edged in gold }\end{array}$ & $\begin{array}{l}\text { - triangular } \mathrm{V} \text { applique } \\
\text { at center front of bodice, } \\
\text { made of silver sequined } \\
\text { fabric with silver braid } \\
\text { on edges } \\
\text { - stops just below } \\
\text { natural waist }\end{array}$ & $\begin{array}{l}\text { - silver double loop } \\
\text { braid at neckline } \\
\text { - silver double loop bow } \\
\text { with long tails stitched } \\
\text { center of waistline }\end{array}$ \\
\hline Decorative Motifs & $\begin{array}{l}\text { - plastic cameo of } \\
\text { Rapunzel stitched at } \\
\text { neckline, not removable. }\end{array}$ & - none & $\begin{array}{l}\text { - applique pink crown } \\
\text { with silver edge on } \\
\text { center of bodice }\end{array}$ \\
\hline Finishing & $\begin{array}{l}\text { - bias edges at } \\
\text { necklines. } \\
\text { - waistline enclosed in } \\
\text { lining. } \\
\text { - waistline gathered in } \\
\text { front, no stretch } \\
\text { - gathered in back with } \\
\text { elastic with stretch }\end{array}$ & $\begin{array}{l}\text { - all edges cover } \\
\text { stitched } \\
\text { - waistline cover } \\
\text { stitched }\end{array}$ & $\begin{array}{l}\text { - cover stitch at neck } \\
\text { with elastic stitched in } \\
\text { but allows for no stretch } \\
\text { - serged at waist } \\
\text { - skirt gathered at waist } \\
\text { to allow for stretching }\end{array}$ \\
\hline \multicolumn{4}{|l|}{ Skirt Elements } \\
\hline Materials & $\begin{array}{l}\text { - } 100 \% \text { polyester layers } \\
\text { - lining light pink } \\
\text { - dark pink tulle layer } \\
\text { - lighter pink tulle layer } \\
\text { - top layer, dark pink } \\
\text { organza with spray on } \\
\text { glitter pattern }\end{array}$ & $\begin{array}{l}\text { - } 3 \text { layers } \\
\text { - light blue tulle layer } \\
\text { - light blue polyester } \\
\text { satin layer } \\
\text { - draped overskirt silver } \\
\text { blue lame polyester, } \\
\text { split at center front, } 3 \text { 3" } \\
\text { pleats stitched into side, } \\
\text { not in back }\end{array}$ & $\begin{array}{l}\text { - } 4 \text { layers } \\
\text { - polyester pink lining } \\
\text { - two layers of light } \\
\text { pink tulle } \\
\text { - over layer } 100 \% \\
\text { polyester pink net with } \\
\text { spray on glitter }\end{array}$ \\
\hline Style & - gathered waistline & - gathered waistline & - gathered waistline \\
\hline
\end{tabular}




\begin{tabular}{|c|c|c|c|}
\hline Description & Disney & Dreampower & $\begin{array}{c}\text { Creative Education } \\
\text { Canada }\end{array}$ \\
\hline Embellishment & $\begin{array}{l}\text { - top layer scattered star } \\
\text { and dot motif pattern } \\
\text { above a border design of } \\
\text { lily motif, with circles. }\end{array}$ & - none & - none \\
\hline Decorative motifs & $\begin{array}{l}\text { - on hem of light pink } \\
\text { tulle layer a pink ribbon } \\
\text { that has printed in repeat } \\
\text { "Daring to Dream" "A } \\
\text { Perfect Princess" } \\
\text { "Always Graceful" }\end{array}$ & - none & - none \\
\hline Finishing & $\begin{array}{l}\text { - lining - narrow serge } \\
\text {-dark pink tulle - } \\
\text { unfinished } \\
\text { - light pink tulle - } \\
\text { ribbon } \\
\text { - top layer narrow serge } \\
\text { with metallic thread }\end{array}$ & $\begin{array}{l}\text { - tulle - unfinished } \\
\text { - satin layer narrow } \\
\text { serge } \\
\text { - lame narrow serge }\end{array}$ & $\begin{array}{l}\text { - lining - narrow serge } \\
\text { - tulle - unfinished } \\
\text { - net- narrow serge with } \\
\text { metallic thread }\end{array}$ \\
\hline
\end{tabular}




\section{Appendix B: Evaluation Stage of the Use-Value Method}

\begin{tabular}{|c|c|c|c|}
\hline Elements Evaluated & Disney & Dreampower & Creative Education Canada \\
\hline $\begin{array}{l}\text { To the Touch of } \\
\text { Hand }\end{array}$ & - crunchy & - soft & - rubbery \\
\hline $\begin{array}{l}\text { Feel Against the } \\
\text { Body }\end{array}$ & - smooth lining & - scratchy from tulle skirt & $\begin{array}{l}\text { - smooth fabrics, } \\
\text { - serged seams are scratchy }\end{array}$ \\
\hline $\begin{array}{l}\text { Wear and Tear } \\
\text { Issues }\end{array}$ & $\begin{array}{l}\text { - glitter falls off } \\
\text { - ribbon on sleeves get } \\
\text { caught on things }\end{array}$ & $\begin{array}{l}\text { - finishes are not binding } \\
\text { for fabric edges }\end{array}$ & -glitter falls Off! \\
\hline Quality of Work & $\begin{array}{l}\text { - high, all seams are } \\
\text { either, enclosed or } \\
\text { finished to no ravel }\end{array}$ & $\begin{array}{l}\text { - serged finish ripples } \\
\text { satin } \\
\text { - threads hanging off }\end{array}$ & $\begin{array}{l}\text { - edges of serging are } \\
\text { visible at hems }\end{array}$ \\
\hline Quality of Materials & $\begin{array}{l}\text { - a lot of different } \\
\text { textures } \\
\text { - durable poly } \\
\text { otherwise. }\end{array}$ & - cheap polyesters & - cheap polyester \\
\hline $\begin{array}{l}\text { Quality of } \\
\text { Embellishment }\end{array}$ & $\begin{array}{l}\text { - glitter falls off } \\
\text { - ribbon edges are sealed }\end{array}$ & $\begin{array}{l}\text { - ribbon edges fraying } \\
\text { - sequins and braid secure }\end{array}$ & $\begin{array}{l}\text { - tails of braid bow are } \\
\text { fraying }\end{array}$ \\
\hline $\begin{array}{l}\text { Donning and } \\
\text { Doffing }\end{array}$ & $\begin{array}{l}\text { - large neckline, over the } \\
\text { head }\end{array}$ & $\begin{array}{l}\text { - over the head, tie at the } \\
\text { side, could be awkward to } \\
\text { tie on oneself }\end{array}$ & $\begin{array}{l}\text { - large neckline, over the } \\
\text { head, } \\
\text { - spaghetti straps are easy to } \\
\text { get tangled up with arms }\end{array}$ \\
\hline Laundry Concerns & $\begin{array}{l}\text { - Glitter! } \\
\text { - Cameo is not } \\
\text { removable } \\
\text { - melting! }\end{array}$ & $\begin{array}{l}\text { - lots of edges to get } \\
\text { caught in the washing } \\
\text { machine }\end{array}$ & $\begin{array}{l}\text { - Glitter! } \\
\text { - ribbon bow. } \\
\text { - melting }\end{array}$ \\
\hline Safety Concerns & $\begin{array}{l}\text { - sleeve detail getting } \\
\text { caught on things }\end{array}$ & $\begin{array}{l}\text { - if not tied on properly } \\
\text { could shift around and get } \\
\text { caught on things }\end{array}$ & $\begin{array}{l}\text { - length? } \\
\text { - length of ribbon braid? }\end{array}$ \\
\hline $\begin{array}{l}\text { Imaginative Play } \\
\text { Value }\end{array}$ & - no additional function & $\begin{array}{l}\text { - adjustable and easy to } \\
\text { layer }\end{array}$ & - no additional function. \\
\hline $\begin{array}{l}\text { Emotional } \\
\text { Response }\end{array}$ & $\begin{array}{l}\text { - surprised at quality. } \\
\text { - saccharin, cheap with } \\
\text { all the glitter } \\
\text { - layers make it feel } \\
\text { poufy and special }\end{array}$ & $\begin{array}{l}\text { - pinafore design works } \\
\text { for simplified princess } \\
\text { shape } \\
\text { - more like an accessory } \\
\text { than a full costume } \\
\text { - love the simplicity }\end{array}$ & $\begin{array}{l}\text { - cheap, finding the } \\
\text { cheapest way to include all } \\
\text { the elements of a Disney } \\
\text { dress or princess } \\
\text { characteristics }\end{array}$ \\
\hline
\end{tabular}




\section{Appendix C: Interpretations of Disney's Cinderella}

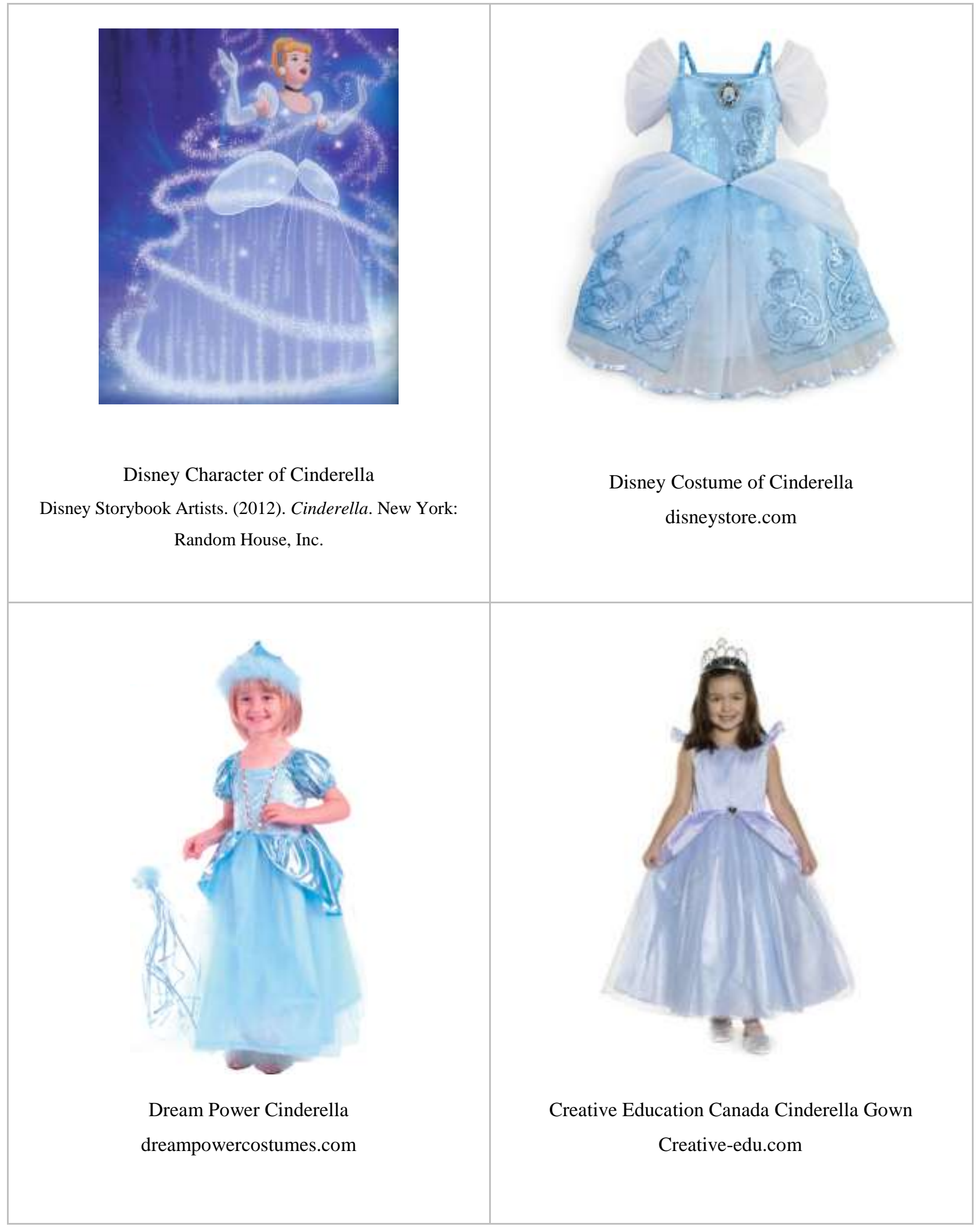




\section{References}

Appadurai, A. (1986). Introduction: Commodities and the politics of value. In A. Appadurai (Ed.), The social life of things: Commodities in cultural perspective (pp. 3-58).

Cambridge, UK: Cambridge University Press.

Armstrong, C. M., \& LeHew, M. L. (2011). Sustainable apparel product development: In search of a new dominant social paradigm for the field using sustainable approaches. Fashion Practice, 3(1), 29-62. doi:10.2752/175693811X12925927157018

Beard, N. D. (2008). The branding of ethical fashion and the consumer: A luxury niche or massmarket reality? Fashion Theory: The Journal of Dress, Body \& Culture, 12(4), 447-468. doi:10.2752/175174108X346931

Black, S. (2008). Eco-chic: The fashion paradox. London, UK: Black Dog.

Buchanan, R. (2001). Design research and the new learning. Design Issues, 17(4), 3-23. doi:10.1162/07479360152681056

Bye, E. (2010). A direction for clothing and textile design research. Clothing \& Textile Research Journal, 28(3), 205-217.

Chapman, J. (2005). Emotionally durable design: Objects, experiences, and empathy. London, UK: Earthscan. doi:10.1177/0887302X10371505

Creative Education of Canada. (2006). Great pretenders. Retrieved from http://www.creativeedu.com/index.php

Dant, T. (1999). Material culture in the social world: Values, activities, lifestyles. Buckingham, UKL: Open University Press.

Disney Consumer Products. (2012). Disney princess. Retrieved from http://tinyurl.com/ck7fafg Dreampower Costumes. (n.d.). Home. Retrieved from http://www.dreampowercostumes.com/ 
Ehrenfeld, J. R. (2004). Searching for sustainability: No quick fix. Reflections, 5(8), 1-13.

Farrer, J. (2011). Remediation: Discussing fashion textiles sustainability. In A. Gwilt \& T. Rissanen (Eds.), Shaping sustainable fashion: Changing the way we make and use clothes (pp. 19-33). London, UK: Earthscan.

Feldman, T. (2012). Cinderella. New York: Random House, Inc.

Fleming, E. M. (1974). Artifact study: A proposed model. Winterthur Portfolio, 9(1), 153-173. doi:10.1086/495828

Fletcher, K. (2008). Sustainable fashion and textiles: Design journeys. London, UK: Earthscan.

Fletcher, K. (2010). Slow fashion: An invitation for systems change. Fashion Practice, 2(2), 259-266.

Fletcher, K. (2011). Post-growth fashion and the craft of users. In A. Gwilt \& T. Rissanen (Eds.), Shaping sustainable fashion: Changing the way we make and use clothes (pp. 165-175). London, UK: Earthscan.

Fletcher, K. (2012). Durability, fashion, sustainability: The process and practices of use. Fashion Practice, 4(2), 221-238. doi:10.2752/175693812X13403765252389

Fletcher, K. T., \& Goggin, P. A. (2001). The dominant stances on ecodesign: A critique. Design Issues, 17(3), 15-25. doi:10.1162/074793601750357150

Fletcher, K., \& Grose, L. (2012). Fashion and sustainability: Design for change. London, UK: Laurence King.

Friedman, J. (1991). Consuming desires: Strategies of selfhood and appropriation. Cultural Anthropology, 6(2), 154-163. 
Gillham, B., \& McGilp, H. (2007). Recording the creative process: An empirical easis for practice-integrated research in the arts. International Journal of Art \& Design Education, 26(2), 177-184.

Gwilt, A., \& Rissanen, T. (2011). Shaping sustainable fashion: Changing the way we make and use clothes. London: Earthscan.

Hethorn, J. (2008). Consideration of consumer desire. In J. Hethorn \& C. Ulasewicz (Eds.), Sustainable fashion: Why now? A conversation exploring issues, practices, and possibilities (pp. 53-76). New York, NY: Fairchild.

Hethorn, J., \& Ulasewicz, C. (2008). Sustainable fashion: Why now? A conversation about issues, practices, and possibilities. New York, NY: Fairchild Books.

Kopytoff, I. (1986). The cultural biography of things. In A. Appadurai (Ed.), The social life of things: Commodities in cultural perspective (pp. 64-91). Cambridge, UK: Cambridge University Press.

Laitala, K., \& Boks, C. (2012). Sustainable clothing design: Use matters. Journal of Design Research, 10(1/2), 121-139.

Lamb, J. M., \& Kallal, M. J. (1992). A conceptual framework for apparel design. Clothing and Textiles Research Journal, 10(2), 42-47. doi:10.1177/0887302X9201000207

Mäkelä, M. (2007). Knowing through making: The role of the artefact in practice-led research. Knowledge, Technology \& Policy, 20(3), 157-163. doi:10.1007/s12130-007-9028-2

Marshall, N. (2008). Dictionary of children's clothes: 1700s to present. London: V \& A Publishing. 
Niinimäki, K., \& Hassi, L. (2011). Emerging design strategies in sustainable production and consumption of textiles and clothing. Journal of Cleaner Production, 19, 1876-1883. doi:10.1016/j.jclepro.2011.04.020

Paoletti, J. B. (2012). Pink and blue: Telling the boys from the girls in America. Bloomington: Indiana University Press.

Pollen, A. (2011). Performing spectacular girlhood: Mass-produced dressing-up costumes and the commodfication of imagination. Textile History, 42(2), 162-180. doi:10.1179/174329511X13123634653820

Prown, J. D. (1982). Mind in matter: An introduction to material culture theory and method. Winterthur Portfolio, 17(1), 1-19. doi:10.1086/496065

Prown, J. D. (1993). The truth of material culture. In S. D. Lubar \& W. D. Kingery (Eds.), History from things: Essays on material culture (pp. 1-19). Washington, DC: Smithsonian Institution Press.

Rosenblad-Wallin, E. (1985). User-oriented product development applied to functional clothing design. Applied Ergonomics, 16(4), 279-287. doi:10.1016/0003-6870(85)90092-4

Rudd, N. A., \& Lennon, S. J. (1994). Aesthetics of the body and social identity. In M. R. DeLong \& A. M. Fiore (Eds.), Aesthetics of textiles and clothing: Advancing multidisciplinary perspectives (pp. 163-175). Monument, CO: International Textile and Apparel Association.

Schultz, S. E., Kleine, R. E., \& Kernan, J. B. (1989). "These are a few of my favorite things": Toward an explication of attachment as a consumer behavior construct. Advances in Consumer Research, 16, 359-366.

Severa, J., \& Horswill, M. (1989). Costume as material culture. Dress, 15, 51-64. 
Steele, V. (1998). A museum of fashion is more than a clothes-bag. Fashion Theory: The Journal of Dress, Body \& Culture, 2(4), 327-335. doi:10.2752/136270498779476109

Townsend, K. (2011). The denim garment as canvas: Exploring the notion of wear as a fashion and textile narrative. Textile: The Journal of Cloth and Culture, 9(1), 90-107. doi:10.2752/175183511X12949158771554

Tranberg Hansen, K. (2003). Fashioning Zambian moments. Journal of Material Culture, 301309.

United Nations General Assembly. (2005). 2005 world summit outcome. Retrieved from http://www.un.org/summit2005/documents.html

Walker, S. (2006). Sustainable by design. London, UK: Earthscan.

The Walt Disney Company. (n.d.). Disney store. Retrieved from http://www.disneystore.com/ World Commission on Environment and Development. (1987). Our common future. Oxford, UK: Oxford University Press. 